\title{
EFFECTS OF TESTOSTERONE ON THE SPATIAL ECOLOGY, COLORATION, AND BRAIN REGIONS IN WESTERN FENCE LIZARD, SCELOPORUS OCCIDENTALIS
}

\author{
A Thesis \\ presented to \\ the Faculty of California Polytechnic State University, \\ San Luis Obispo
}

In Partial Fulfillment

of the Requirements for the Degree

Master of Science in Biological Sciences

\author{
by
}

Rachel Catharine Wilson

September 2015 
(C) 2015

Rachel Catharine Wilson

ALL RIGHTS RESERVED 


\section{COMMITTEE MEMBERSHIP}

TITLE:

Effects of testosterone on the spatial ecology, coloration, and brain regions in western fence lizard, Sceloporus occidentalis
AUTHOR:
Rachel Catharine Wilson

DATE SUBMITTED:

September 2015

COMMITTEE CHAIR: Christy Strand, Ph.D.

Associate Professor of Biological Sciences

COMMITTEE MEMBER: Emily Taylor, Ph.D.

Associate Professor of Biological Sciences

COMMITTEE MEMBER: Sean Lema, Ph.D.

Associate Professor of Biological Sciences 


\begin{abstract}
Effects of testosterone on the spatial ecology, coloration, and brain regions in western fence lizard, Sceloporus occidentalis

Rachel Catharine Wilson
\end{abstract}

An organism's spatial ecology allows for access to essential resources such as food, mates, and escape from predators. Home range size, or the total area an organism inhabits, varies in relation to numerous factors including seasonality. During the breeding season, home range size increases in males across taxa. In addition, males usually also have larger home range sizes than females. This implicates testosterone $(\mathrm{T})$ as a possible mediator of this relationship. Indeed, $T$ causes an increase in home range size of males in numerous species of lizards. In addition to $T$ causing an increase in home range size, it also causes an increase in coloration, which is used as a signal to deter or elicit aggressive behaviors in lizards. Potentially, contests are less common in natural settings than in the lab due to this signaling despite increased frequency overlap of home ranges in males. The larger the home range size of males, mediated through an increase in $\mathrm{T}$, the more overlap with conspecifics. With this increase in spatial demand, or home range size, there is often a corresponding increase in spatially related brain regions. In reptiles, these brain regions are the medial and dorsal cortices (MC and DC respectively). The increase in cortical brain region size due to an increase in spatial demand may be mediated by an increase in neurogenesis. Proliferation of neurons occurs along the ventricles and radiate to numerous regions in the brain including the $\mathrm{MC}$. With respect to the $\mathrm{MC}$, immature neurons, which express the protein doublecortin (DCX), migrate from the ventricles, through the inner plexiform layer and are integrated into the cell layer. Because DCX is only expressed in recently born, migrating neurons, it can be used to measure neurogenesis. In mammals and birds, neurogenesis and growth of certain brain regions is affected by steroid hormones, including T. Here we tested two hypotheses: (1) T affects the home range size of Sceloporus occidentalis and (2) cortical brain region volumes are related to home range size and/or $\mathrm{T}$ which is mediated through changes in rates of neurogenesis. We surgically castrated individuals and implanted subjects with either a Tfilled implant or blank implant and then released them at their initial capture sites. In addition to these castrated individuals, subjects not subjected to castration served as unmanipulated controls. Home range size of individuals in the field was quantified using a global positioning system (GPS) unit and later delineating those GPS points using minimum convex polygons (MCPs). We predicted that (1) castrated, T-treated lizards and unmanipulated control lizards would have larger home range sizes than castrated, control lizards c and (2) MC and DC cortices would be larger in volume and contain more DCXimmunoreactive cells in the lizards with the highest circulating $\mathrm{T}$ levels and with the largest home range sizes. We found that increased $\mathrm{T}$ caused an increase in the number of blue abdominal scales. We found no differences in home range size relating to $\mathrm{T}$. Likewise, $\mathrm{T}$ did not affect MC volumes. However, we did observe a decrease in DC volume with increasing plasma levels of $\mathrm{T}$. Because $\mathrm{T}$ did not affect home range size, it follows that we did not find an effect of $\mathrm{T}$ on $\mathrm{MC}$ volume. However, the significant result of $\mathrm{T}$ causing a decrease in DC volume implies a possible trade off with regards to 
energetics and the maintenance of brain region volumes as prior research indicates that $\mathrm{T}$ in increases energy expenditure and decreases foraging efforts.

Keywords: reptile, spatial ecology, home range, neuroplasticity, testosterone 


\section{ACKNOWLEDGMENTS}

I would like to thank Griffin Capehart, Michael DeLea, Jeanette BarrigaHernandez, Haley Ehlers, Liz Trujillo, Kelly Hood, Rachel Donaghue, Silvia Rodriguez, and Veronica Flesch for assistance in the field and lab. I would like to especially thank Christy Strand and Emily Taylor for their invaluable professional input and friendship over the course of my career. I would also like to thank the department of Natural Resources Management and Environmental Sciences for allowing me to use their GPS unit and Russell White for all his help with learning to use the GPS unit and ARCGIS software. I would also like to acknowledge Susannah French and her lab at Utah State University for performing the radioimmunoassay on my blood samples and Dale DeNardo at Arizona State University for performing the castration surgeries. And lastly, I would like to acknowledge California Polytechnic State University Department of Biological Sciences for funding this research. 


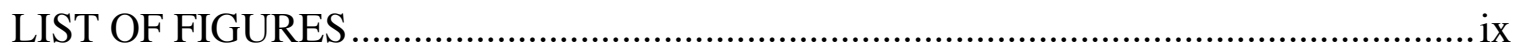

INTRODUCTION: SPATIAL ECOLOGY AND CORTICAL BRAIN REGIONS ........... 1

1. CHAPTER 1. EFFECT OF TESTOSTERONE ON HOME RANGE SIZE AND COLORATION; AND A COMPARISON OF HOME RANGE QUANTIFICATION TECHNIQUES

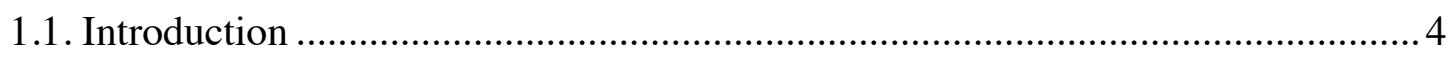

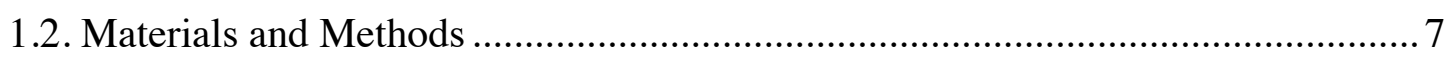

1.2.1. Field experiment procedures .................................................................

1.2.2. Surgical procedure ............................................................................ 8

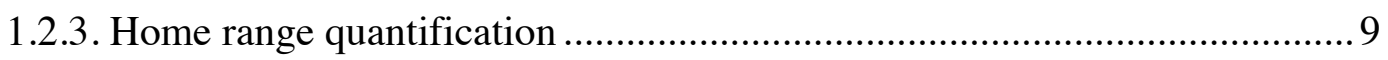

1.2.4. Quantification of ventral body coloration ................................................... 10

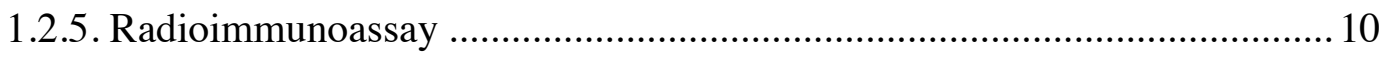

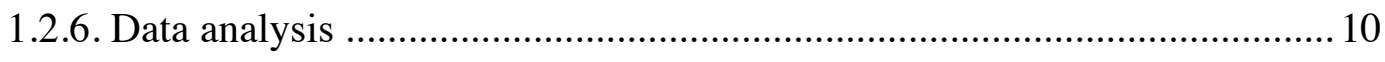

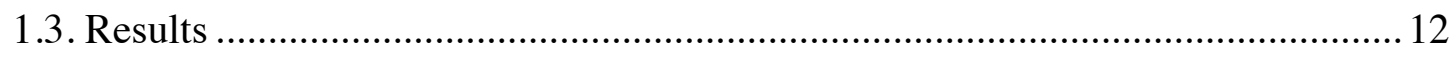

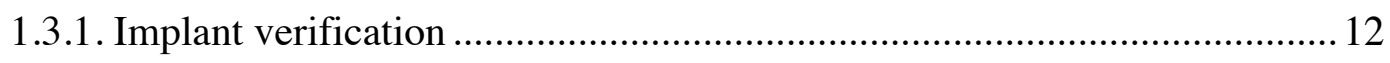

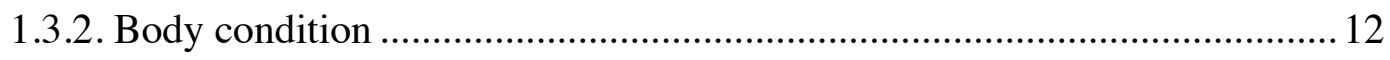

1.3.3. Testosterone effect on home range size .................................................... 12

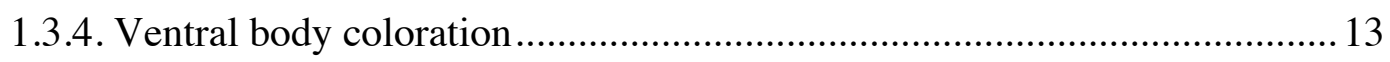

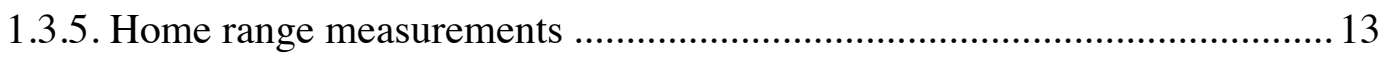

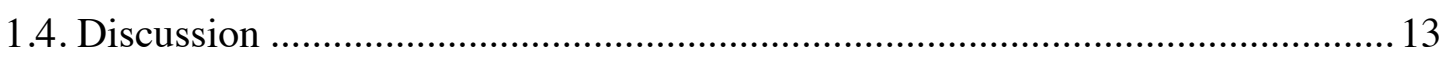

1.4.1. Testosterone effect on home range size ..................................................... 14

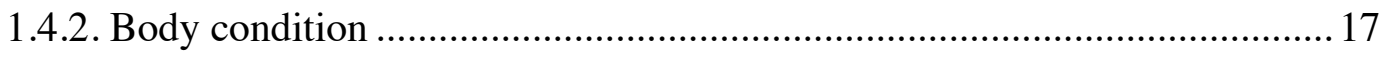

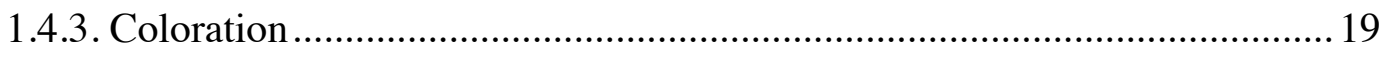


1.4.4. Minimum number of points for home range measurement

1.4.5. Comparison of home range size quantification techniques .......................2 21

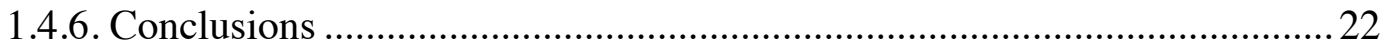

2. CHAPTER 2. EFFECT OF TESTOSTERONE ON BRAIN REGIONS IN FREE-LIVING WESTERN FENCE LIZARDS ..................................................... 23

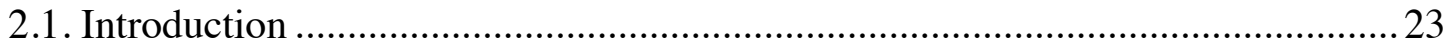

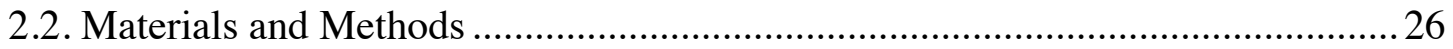

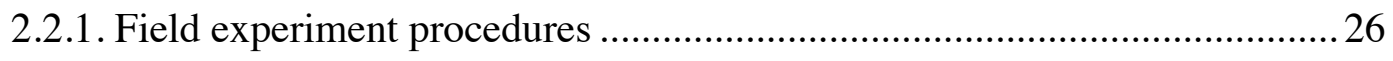

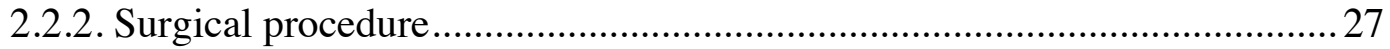

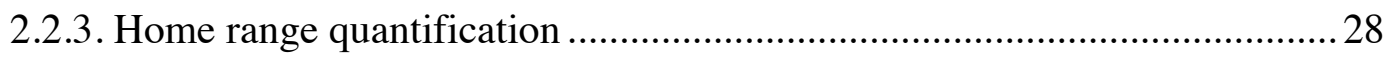

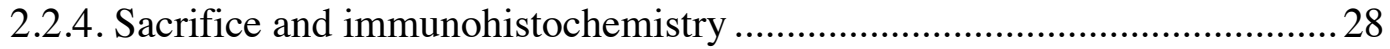

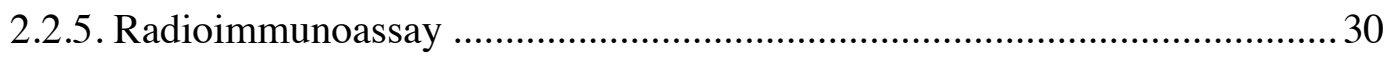

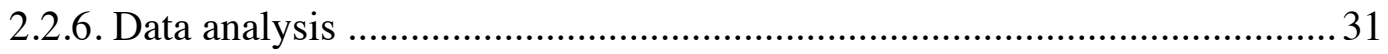

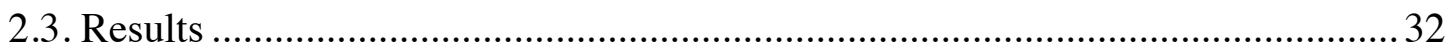

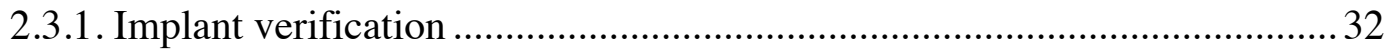

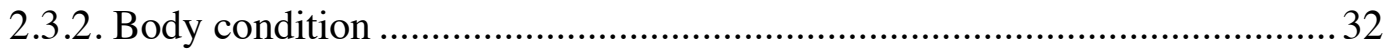

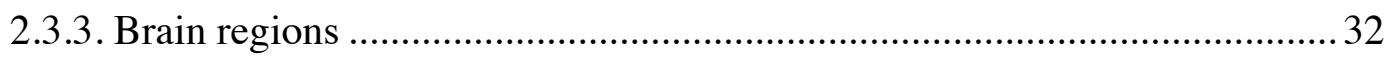

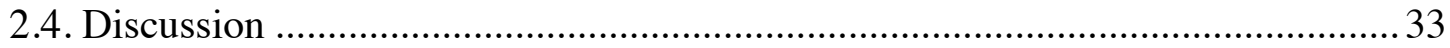

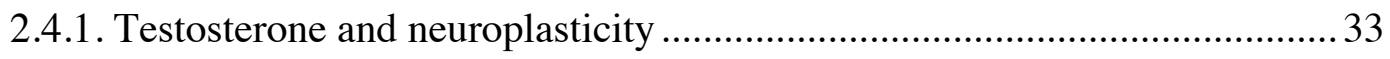

2.4.2. Spatial ecology and neuroplasticity ............................................... 38

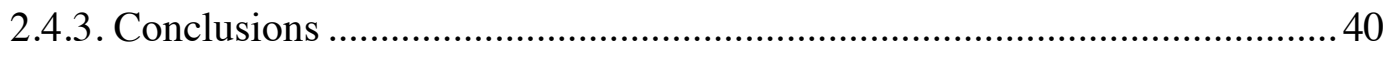

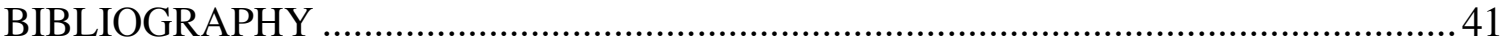

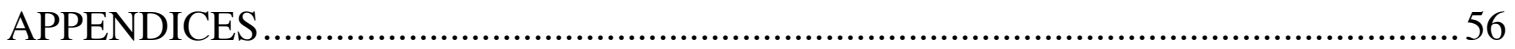


Figure

\section{LIST OF FIGURES}

Figure 1.1. Testosterone $(\mathrm{T})$ levels $(\mathrm{ng} / \mathrm{mL})$ plotted as mean $\pm \mathrm{SEM}$

values of adult male Sceloporus occidentalis

Figure 1.2. Body condition (mean \pm SEM) of testosterone $(\mathrm{T})$ and

blank implanted (Bl) individuals of adult male Sceloporus occidentalis

Figure 1.3. Relationship between snout-vent length (SVL) and body mass of recaptured individuals of adult male Sceloporus occidentalis....................................................58

Figure 1.4. Relationship between testosterone (T) and body mass controlling for snout-vent length (SVL) of adult male Sceloporus occidentalis.

Figure 1.5. Mean minimum convex polygons (MCP; $\left.\mathrm{m}^{2} \pm 1 \mathrm{SEM}\right)$ of adult male Sceloporus occidentalis

Figure 1.6. Mean log transformed minimum convex polygons (MCP $; \mathrm{m}^{2}+$ S.E.M) of adult male Sceloporus occidentalis

Figure 1.7. Relationship between the number of points used to delineate minimum convex polygon and $\log \mathrm{MCP}\left(\mathrm{m}^{2}\right)$ of adult male Sceloporus occidentalis

Figure 1.8. Mean number of blue abdominal scales (count $\underline{+}$ SEM) of adult male Sceloporus occidentalis

Figure 1.9. Change in minimum convex polygons (MCPs) relative to the number of spatial observation points used to delineate the MCP of adult male Sceloporus occidentalis

Figure 1.10. Comparison of home range size $\left(\mathrm{m}^{2} \pm\right.$ S.E.M) measurement techniques of adult male Sceloporus occidentalis

Figure 2.1. Cresyl violet stained section through the telencephalon of an adult male Sceloporus occidentalis (20x)

Figure 2.2. Doublecortin-immunoreactive (DCX-ir) cells in the medial cortex (MC; 200x) of adult male Sceloporus occidentalis

Figure 2.3. Model residuals of all variables in the model excluding plasma testosterone (T) concentration $(\mathrm{ng} / \mathrm{mL})$ for the medial cortex $(\mathrm{A})$ and dorsal cortex (B) of adult male Sceloporus occidentalis. 
Figure 2.4. Relationship between total telencephalon volumes (TT; $\mathrm{mm}^{3}$ ) excluding the region of interest and the medial cortex (MC; A) and dorsal cortex (DC; B) of adult male Sceloporus occidentalis

Figure 2.5. Relationship between plasma testosterone ( $\mathrm{T}$ ) concentration $(\mathrm{ng} / \mathrm{mL})$ and the medial cortex $(\mathrm{MC} ; \mathrm{A})$ and dorsal cortex $(\mathrm{DC} ; \mathrm{B})$ controlling for size of total telencephalon (TT) of adult male Sceloporus occidentalis.

Figure 2.6. Relationship between home range size calculated as minimum convex polygon (MCP) and the medial cortex (MC; A) and dorsal cortex (DC; B) controlling for size of total telencephalon (TT) of adult male Sceloporus occidentalis

Figure 2.7. Relationship between plasma testosterone ( $\mathrm{T}$ ) concentration (ng/mL) and model residuals of the density of doublecortin-immunoreactive (DCX-ir; count $/ \mathrm{mm}^{3}{ }^{3} \mathrm{SEM}$ ) cells in the cell layer (CL; A) and inner plexiform layer (IPL; B) of adult male Sceloporus occidentalis

Figure 2.8. Relationship between total telencephalon volume (TT; $\mathrm{mm}^{3}$ ) excluding the nucleus sphericus (NS) and the NS (A) and the effect of plasma testosterone $(\mathrm{T})$ concentration $(\mathrm{ng} / \mathrm{mL})$ on NS volume controlling for TT (B) of adult male Sceloporus occidentalis 


\section{INTRODUCTION: Spatial ecology and cortical brain regions}

The spatial ecology of an organism allows for resource allocation, access to mates, and escape from predators. The area an organism inhabits is referred to as the home range (Sheldahl and Martins, 2000). Defending a subsection of an organism's home range, or territoriality is essential for individual survival and fitness to ensure access to numerous ecological factors such as food, water, mates, and/or basking sites (Haenel et al., 2003a). However, in cryptic species conspecific interactions may be difficult to observe or quantify (Moore et al., 2009) and therefore it may be difficult to discern an organism's territory.

The plasticity of home range size depends on numerous environmental parameters: habitat productivity (Kerr and Bull, 2006), population density (Trewhella et al., 1988), and season (Sheldahl and Martins, 2000; Haenel et al., 2003a; Wone and Beauchamp, 2003). Across numerous taxa, home range size increases with decreased habitat productivity (Lashley et al., 2015; Schoepf et al., 2015; McClintic et al., 2014; Morellet et al., 2014; van Beest et al., 2011; Whitaker et al., 2007; Kerr and Bull, 2006; Herfindal et al., 2005; Relyea et al., 2000), decreased population density (Schoepf et al., 2015; Whyte et al., 2013; Scoular et al., 2011; van Beest et al., 2011; Whitaker et al., 2007; Dahle and Swenson, 2003; Trewhella et al., 1988), and during the breeding season (Morellet et al., 2013; Whitaker et al., 2007; Perelberg et al., 2003; Wone and Beauchamp, 2003; Krasinska et al., 2000; Okarma et al., 1998; Phillips et al., 1998). Along with home range size increasing during the breeding season, males tend to have larger home range sizes than female conspecifics (John-Alder et al., 2009; Abell, 1999; Smith, 1995). This indicates testosterone (T) as a likely candidate to mediate this spatial 
relationship as it also increases during the breeding season; indeed, in some lizard species, T causes an increase in home range size (Uta stansburiana: DeNardo and Sinervo, 1994; Sinervo et al., 2000; Sceloporus undulatus: Cox et al., 2005a; and John-Alder et al., 2009). However, in Algerian sand lizards (Psammodromus algirus), $\mathrm{T}$ does not affect home range size (Salvador et al., 1996).

In many animals, increased spatial demand results in increased growth of the hippocampus, a brain region involved in processing spatial memory (Humans: Maguire et al., 2006; Maguire et al., 2000; Rats: Drapeau et al., 2003; Roof and Havens, 1992; Birds: LaDage et al., 2010; Hoshooley et al., 2006). For instance, in shiny cowbirds (Molothrus bonariensis), females have enhanced spatial memory compared to male conspecifics because they are the sole locators of broods to parasitize, and this is reflected in larger hippocampus volumes in females (Reboreda et al., 1996). In reptiles, the medial and dorsal cortices (MC and DC, respectively) are considered hippocampal homologues and similarly display plasticity with regards to spatial ecology. In male Northern Pacific rattlesnakes (Crotalus oreganus), short distance translocations caused increased home range size and an increase in MC volume (Holding et al., 2012). In male side-blotched lizards (Uta stainsburiana), non-territorial morphs had smaller DC volumes than morphs holding larger territories (LaDage et al., 2009). Furthermore, territorial male sideblotched lizards had a significantly higher instance of neurogenesis compared to nonterritorial males in large enclosures (LaDage et al., 2013). This relationship of increased spatial demand resulting in increased growth of spatial related brain regions is likely due to the necessity of remembering resource locations through encoding and integrating memory (Fagan et al., 2013). 
Brain morphology is regulated by physiological factors including energetics (Fagan et al., 2013), glucocorticoids (Galea, 2008), and gonadal hormones (Mirescu and Gould, 2006). One of the best-studied examples is the effect of $\mathrm{T}$ on the seasonal growth of the brain regions involved with singing behavior in songbirds. T primarily controls the increase in song control region volumes during the breeding season, although other factors such as social context and photoperiod can affect growth independently (Balthazart et al., 2010). Furthermore, in some regions, the increase in volume is mediated through changes in neuron survival and neurogenesis. For example, $\mathrm{T}$ causes an increase in cell proliferation (Barker et al., 2014), and a decrease in $\mathrm{T}$ decreases neuron number (Thompson et al., 2007). However, brain region growth can be constrained by energetics due to the necessity of molecular modification in order to store and integrate memories (Fagan et al., 2013).

As $\mathrm{T}$ is responsible for numerous sexual dimorphisms, perhaps it is also responsible for increased spatial navigation abilities in males (Clint et al., 2012). In lizards (Sceloporus jarrovi), territoriality is a male specific trait displayed in response to elevated levels of $\mathrm{T}$ during the breeding season (Moore, 1988). In U. stansburiana, males with higher T levels had larger home range sizes (DeNardo and Sinervo, 1994; Sinervo et al., 2000). Furthermore, territorial male U. stansburiana morphs have innately higher T levels compared to non-territorial conspecifics (Sinervo et al., 2000). To further elucidate the relationships between T, spatial memory, and neuroplasticity, I investigated the effect of $\mathrm{T}$ on home range size and neuroplasticity of cortical brain regions in adult male Sceloporus occidentalis. 


\section{CHAPTER 1: Effect of testosterone on home range size and coloration; and a comparison of home range quantification techniques}

\subsection{Introduction}

Spatial ecology is an important aspect of organismal biology as it allows for resource availability, escape from predators, and access to mates to name a few. Some aspects of spatial ecology, such as activity patterns and movements, have the ability to elucidate organism's behavior and ecology (Wone and Beauchamp, 2003). Home range is defined as the space an organism utilizes in its daily activities whereas territory is defined as the area an organism defends (Sheldahl and Martins, 2000). Territoriality is a behavior displayed in order to defend food, water, mates, and/or basking sites (Haenel et al., 2003a). Due to extensive and high variation in territorial behaviors and home range size, lizards have been identified as model organisms for studying spatial ecology (Haenel et al., 2003a).

Home range size varies in relation to several environmental factors: habitat productivity (Kerr and Bull, 2006), population density (Trewhella et al., 1988), and season (Sheldahl and Martins, 2000; Haenel et al., 2003a; Wone and Beauchamp, 2003). Despite, other environmental determinants of home range size, generally home range and/or territories sizes increase during the breeding season (Néstor et al., 2010; JohnAlder et al., 2009; Wone and Beauchamp, 2003; Baird et al., 2001). Male lizards with larger home range sizes have more access to female conspecifics through increased home range overlap (Haenel et al. 2003a; Abell, 1999; Smith, 1995) and increased overlap frequency with females results in increased fitness of males through increased progeny 
(John-Alder et al., 2009; Haenel et al. 2003a; Sinervo et al., 2000). However males that defend larger territories also have lower survivorship (Sinervo et al., 2000).

Testosterone (T) is a sex steroid hormone that increases during the breeding season (John-Alder et al., 2009). Generally, male lizards with higher testosterone (T) levels have larger home range sizes (DeNardo and Sinervo, 1994; Sinervo et al., 2000; Cox et al., 2005a; and John-Alder et al., 2009) and therefore appear to increase male fitness since increased home range size increases frequency of home range overlap with females. However, $\mathrm{T}$ also increases aggressive behaviors and may also mediate a decrease in survivorship since defending larger territories results in lower survivorship. Therefore, there are fitness related trade offs associated with $\mathrm{T}$, as in most biological paradigms.

In addition to increased home range size, $\mathrm{T}$ has other physiological effects. Male lizards with elevated $\mathrm{T}$ levels display an increase in aggressive behaviors (Urosaurus ornatus: Weiss and Moore, 2004; Paroedura picta: Golinski et al., 2014). Intrasexual contests, however, are rarely seen in the field despite high home range overlap among males (Haenel et al., 2003b). In the lab, coloration predicts contest winners: in male brown anoles (Anolis sagrei), higher instances of UV, red, and orange coloration in the dewlap predicted winners of contests (Steffen and Guyer, 2014). As coloration acts as a signal to either deter or elicit aggressive behaviors (Lopez et al., 2004), perhaps contests are avoided in the field due to the perception of coloration as a statement of status (Thompson and Moore 1991). Indeed, escalation of aggressive behaviors is costly (Marler and Moore, 1988 and 1989). 
With regards to $\mathrm{T}$ and its effects on coloration, exogenous $\mathrm{T}$ treatment caused an increase in black throat patch size and blue and black abdominal patch size in Sceloporus undulatus (Cox et al., 2005b). Likewise, in Yarrow's spiny lizards (S. jarrovii), castration of juvenile males resulted in decreased hue and saturation of blue abdominal patches (Cox et al., 2008). Presumably, males with higher T have more intense coloration, deterring conspecifics from encroaching on their home range sizes and allowing increased access to females thereby increasing fitness through increased progeny and avoiding potentially costly intrasexual contests.

Despite a somewhat large body of evidence on closely related Sceloporus species, to date, there doesn't appear to be much literature investigating spatial ecology related factors and their determinants in western fence lizards (S. occidentalis). Therefore, this study consisted of methodological and physiological investigations regarding home range size in adult male $S$. occidentalis. With regards to the methodology, we were interested in determining the minimum number of sightings needed to accurately quantify home range size. With regards to physiology, we were interested in the potential relationship among $\mathrm{T}$, home range size, and coloration. We hypothesized that testosterone affects home range size and coloration. We predicted that increased testosterone would cause an increase in home range size and an increase in the number of colored throat and abdominal scales on an individual. 


\subsection{Materials and Methods}

\subsubsection{Field experiment procedures}

Adult male S. occidentalis were captured by hand-held noose from two sites located on the California Polytechnic State University San Luis Obispo campus. Collecting permits were obtained through California Department Fish and Wildlife (permit number SC-11933), and all procedures were approved by the Cal Poly Institutional Animal Care and Use Committee (permit number \#1406). Individuals were collected from two differing sites. Anecdotally, site 1 had less of a slope, was dominated by mostly grasslands with some shrub and tree vegetation, and faced southeast. Site 2 had much more of a northeast facing slope and was dominated by mostly grasslands. Individuals $(\mathrm{n}=14)$ from site one $\left(35^{\circ} 19^{\prime} 15^{\prime} \mathrm{N}, 120^{\circ} 40^{\prime} 51^{\prime \prime} \mathrm{W}\right)$ were captured and transported to the lab over a three day period (April 7-9, 2014). Individuals $(n=10)$ from site two

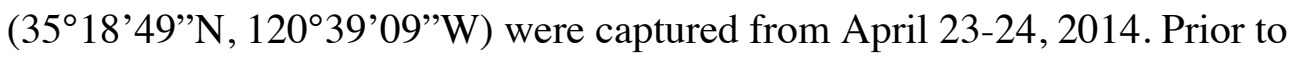
transportation to the lab, individuals were uniquely marked by toe--clipping and color coding on the dorsal caudal surface with paint pens for identification. Snout-vent length

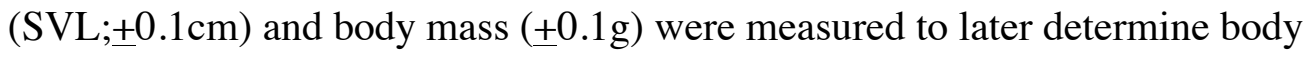
condition. Initial blood samples were taken to measure circulating T levels. Blood samples were collected in the field using heparinized microhematocrit tubes to rupture the retro-orbital sinus. On average, blood samples were collected within $3+0.22 \mathrm{~min}$ (mean+standard error of the mean (SEM)) after capture. Blood samples were kept on ice and several hours later transported to the lab, and centrifuged for five minutes at 10,000 rpm. Plasma was collected and stored at $-80^{\circ} \mathrm{C}$ until processing. Twenty-one 
individuals were captured, marked, and immediately released. These individuals served as unmanipulated controls. Unfortunately we did not measure SVL, body mass, or collect blood samples for these individuals and therefore cannot include them in the repeated measures analysis of covariance (see below).

\subsubsection{Surgical procedure}

Bilateral castration surgeries occurred 4-36 hours after initial capture.

Individuals were subjected to deep anesthesia through inhalation of isoflurane. A bilateral 3to 5-mm incision was made through the integument and musculature through which the testes were excised by gently teasing connective tissue away from the testes using forceps (DeNardo and Licti, 1993). After removal of the testes, 12 individuals received a T--filled implant and the remaining individuals $(\mathrm{n}=12)$ received a blank implant before suturing the incision. Implants were 5mm segments of Silastic diffusion tubing (Dow Corning, Clarkesville, TN, U.S.A.: 1.47 inner diameter, $1.96 \mathrm{~mm}$ outer diameter), capped and sealed with silicon caulking (Momentive Performance Materials Inc., Huntersville, NC, U.S.A.), and filled with either three millimeters of crystalline testosterone propionate (Sigma-Aldrich, St. Louis, MO, U.S.A.; T implant) or silicon caulking (blank implant). After assembly, $\mathrm{T}$ implants weighted $16.05 \pm 0.016 \mathrm{~g}$ while blank implants weighed $16.8 \pm 0.09 \mathrm{~g}$. Subjects were released back to their capture sites after one day to recover from the surgery. After 7 weeks, individuals were recaptured and SVL, body mass, and blood samples were retaken [ $\mathrm{n}=4$ individuals per group [T implanted, blank implanted, and unmanipulated controls)]. 


\subsubsection{Home range quantification}

The location of each individual $(\mathrm{N}=45)$ was determined approximately every other day by visual inspection of the general area where lizards were initially captured and released. On average, lizards were sighted $12 \pm 0.9$ times during the study. When a lizard was sighted, the location of that lizard was taken using a TopCon GM2 global positioning system (GPS) unit (Accuracy of \pm 1 meter; Topcon Positioning Systems Inc., Livermore, $\mathrm{Ca}$, USA). Home range was determined by delineation of these points using $95 \%$ and 100\% minimum convex polygons (GIS MCP) with ARCGIS version 9.2 (ERSI, Redlands, Ca, USA). We found that both the $95 \%$ and $100 \%$ GIS MCPs were identical and therefore only report $100 \%$ GIS MCP values below. We were also interested in determining if and to what extent measurement technique affects home range size estimates. Therefore, we determined home range size using a second technique by photographing the location where each subject was observed. After the time of recapture those photographs were used as references to mark prior locations with flags. Distances between flags were measured using a tape measure to determine segment lengths; angles between segments were measured with a compass. These measurements were used to configure polygons, here after referred to as manual HR measurements, in AutoCAD software (v. 2014, Autodesk, Inc., San Rafael, Ca, USA). Manual HR measurements were taken a priori, and resulted in some concave measurements. To determine the minimum of sightings needed to obtain an accurate home range size, we randomly removed one GPS point at a time and then delineated MCPs until only three GPS points were delineated using ARCGIS. 


\subsubsection{Quantification of ventral body coloration}

Photographs of individuals ( $\mathrm{n}=4$ per group) were also taken at the time of recapture using a Nikon D60 camera. Individuals were brought back to the lab and placed under a stand holding the camera situated directly beneath artificial lighting to ensure equal distance to the subject. We exhaustively counted the total number of blue and black abdominal scales and blue chin scales using Adobe Photoshop CS5.

\subsubsection{Radioimmunoassay}

Radioimmunoassay (RIA) was performed to determine $\mathrm{T}$ levels in lizards prior to surgical treatment and at recapture. All samples were analyzed in a single assay, and T concentrations were assayed according to a previously established protocol (Moore, 1986; French et al., 2010). Briefly, 30\% ethyl acetate/isooctane extractions were performed then separated, dried, and resuspended in $10 \%$ ethyl acetate in isooctane. Testosterone was separated from samples in a $20 \%$ elution of ethyl acetate/isooctane. Samples were collected in vials, dried, and re-suspended in PBS buffer. A duplicate aliquot of each sample was assayed for $\mathrm{T}$ levels. The intra-assay coefficient of variation was $0.098 \%$.

\subsubsection{Data analysis}

Analysis of variance (ANOVA) was utilized to determine if the three groups differed in T levels. Body condition was determined by finding residuals after regressing log transformed SVL and body mass. To determine if T affected body

condition, we ran a repeated measures ANOVA with group, time (body condition at 
the time of surgery and also at the time of recapture), and the interaction between group and time as factors. We decided to run multiple regressions instead of analysis of covariance to analyze the data because our T-treatment resulted in a wide variation of $\mathrm{T}$ levels and our low recapture rate. We analyzed the effect of body mass controlling for SVL using in all recaptured individuals. We analyzed the effect of T on home range size using log-transformed GIS MCP as the response variable, $\log \mathrm{T}$ and the number of sightings as predictor variables and site as a cofactor. To determine the minimum number of sightings needed to obtain an accurate home range size, we ran a repeated measures ANOVA with number of points delineated, as a categorical variable, and time as factors. A repeated measures ANOVA was ran to compare the two home range size quantification techniques with measurement technique as the factor. To determine if $\mathrm{T}$ treatment affected the number of colored scales, predictor variables included $\log$ T, SVL, site, and $\log$ GIS MCP. All statistics were run in JMP Pro 11 (SysStat software, Inc. Point Richmond, CA, USA). Any data not meeting test assumptions were log or square root transformed. The number of blue abdominal scales violated assumptions after attempting multiple transformations. Therefore, a non-parametric test (Kruskal-Wallis test) was conducted to determine if group affected the number of blue abdominal scales. All parameters are reported as means $\underline{ \pm}$ one standard error of the mean (SEM) unless otherwise noted. 


\subsection{Results}

\subsubsection{Implant verification}

Castration and implantation significantly affected T levels (Figure 1.1; $\left.\mathrm{F}_{2,11}=10.08, \mathrm{p}=0.005\right)$. Individuals with $\mathrm{T}$ implants had the highest levels of $\mathrm{T}$, followed by the control group, and then the castrated blank implanted group $(\mathrm{p}<0.05)$.

\subsubsection{Body condition}

Comparing $\mathrm{T}$ implanted and blank implanted individuals over the course of the experiment, there was no effect of group, time, or group*time on body condition (Figure 1.2; Group: $\mathrm{F}_{1,6}=3.8, \mathrm{p}=0.099$; Time: $\mathrm{F}_{1,6}=0, \mathrm{p}=1$; Time* group: $\mathrm{F}_{1,6}=0.44$, $\mathrm{p}=0.533$ ). Comparing all recaptured lizards, snout-vent length positively correlated with lizard mass (Figure 1.3; $\mathrm{R}^{2}=0.75, \mathrm{~F}_{1,9}=18.14, \mathrm{p}=0.002$ ). After controlling for variation in SVL, the negative relationship between $\mathrm{T}$ and lizard weight approached significance (Figure 1.4; $\mathrm{F}_{1,9}=4.02, \mathrm{p}=0.076$ ).

\subsubsection{Testosterone effect on home range size}

T did not influence GIS MCP (Figure 1.5; $\mathrm{F}_{2,17}=0.05, \mathrm{p}=0.96$ ). However, we did observe variation in GIS MCP between sites, with males at site two exhibiting larger home ranges compared to males at site one (Figure 1.6; $\mathrm{F}_{1,17}=5.49, \mathrm{p}=0.032$ ). Also, GIS MCPs increased with increasing number of GPS points (Figure 1.7; $\left.\mathrm{F}_{1,17}=4.95, \mathrm{p}=0.04\right)$. 


\subsubsection{Ventral body coloration}

The number of blue abdominal scales was affected by T treatment (Figure 1.8; $\left.\mathrm{H}_{2}=9.07, \mathrm{p}=0.011\right)$. $\mathrm{T}$ implanted individuals had significantly more blue abdominal scales than blank implanted individuals $(\mathrm{p}<0.05)$. Control individuals did not significantly differ from $\mathrm{T}$ or blank implanted individuals $(\mathrm{p}>0.05)$. $\mathrm{T}$ did not predict

the number of black abdominal scales or blue chin scales (Black abdominal: $\mathrm{F}_{1,9}=0.31$, $\mathrm{p}=0.592$; Blue chin: $\left.\mathrm{F}_{1,9}=1.02, \mathrm{p}=0.365\right)$.

\subsubsection{Home range measurements}

There was a significant difference in the number of points delineated to determine GIS MCPs (Figure 1.9; $\mathrm{F}_{11}=49.41, \mathrm{p}<0.001$ ). Post-hoc tests revealed the minimum number of sightings needed to obtain an accurate home range size for $S$. occidentalis was five points.

Manual MCP and GIS MCP measurements significantly differed from one another (Figure 1.10, $\left.\mathrm{R}^{2}=0.85, \mathrm{~F}_{1,11}=11.00, \mathrm{p}=0.0491\right)$. Log transformed GIS MCPs were larger on average than log transformed manual MCP measurements (logGIS MCP: $4.92 \pm 0.28 \mathrm{~m}^{2}$; log manual MCP: $4.43 \pm 0.28 \mathrm{~m}^{2}$ ). These measurements were highly correlated $\left(\mathrm{R}^{2}=0.85\right)$.

\subsection{Discussion}

We did not find evidence to support that $\mathrm{T}$ affects home range size, but we found evidence to support that $\mathrm{T}$ affects the physiology of western fence lizards. The aim of this study was to determine the effect of ecologically relevant doses of $\mathrm{T}$ on 
home range size and coloration, however our treatment resulted in pharmacological doses of T. Our implants were constructed following the methods of a previous researcher who obtained ecologically relevant doses (Pollock et al., 2012). Nevertheless, this dose could have impacted our lizards adversely and may disallow our findings to be extrapolated to natural conditions.

\subsubsection{Testosterone effect on home range size}

We did not find evidence for a relationship between $\mathrm{T}$ and home range size, which is inconsistent with prior research on other species of lizards (DeNardo and Sinervo, 1994; Sinervo et al., 2000; Cox et al., 2005a; and John-Alder et al., 2009). However, our results are consistent with previous research performed on $S$. occidentalis (Pollock et al., unpublished). Our results provide further evidence that in adult male western fence lizards, $\mathrm{T}$ does not affect home range size. It seems likely that the T-home range relationship may be species specific as this relationship is not present in Algerian sand lizards (Psammodromus algirus) either (Salvador et al., 1996). Perhaps, home range size is constrained by another factor such as body condition (discussed below) or resources. Shelter positively relates and food availability negatively relates to home range size (Anderson et al., 2005; Fisher, 2000 respectively). If shelter, food availability, and access to females were all widely dispersed, then our all lizards in the studied population, regardless of $\mathrm{T}$ would have to cover larger areas of habitat in order to survive and reproduce.

Although we do not have evidence that $\mathrm{T}$ influences home range size in $S$. occidentalis, $\mathrm{T}$ may influence other spatial ecological factors such as territory size and/or movements. Castration reduces an individual's ability to obtain territories in 
brown anoles (Tokarz, 1995). Because territory is defined as the space in which a lizard defends its home range, we were unable to quantify territory size due to the inability to differentiate between courtship and aggressive displays since we only sexed the experimental males and no other conspecifics that were observed interacting with marked males. However, T may not be the sole endocrine regulator of territorial behaviors; treating $S$. jarrovi males with $\mathrm{T}$ in the non-breeding season did not rescue territorial behaviors to the same extent as during the breeding season (Moore and Marler, 1987). In addition, song sparrows (Melospiza melodia) displayed aggressive behaviors towards intruders during the non-breeding season (Wingfield and Soma, 2002). Corticosterone (CORT) seems like a potential candidate involved in territoriality as it increases in response to both the introduction of intruders (Hanley and Stamps, 2002; Klukowski and Nelson, 1998) and in response to increased aggression and winning contests in lizards (Knapp and Moore, 1995; Baird et al., 2014). After an encounter, CORT increased one day and remained elevated until day three in winners but not in losers (Knapp and Moore, 1995). However, in male copperheads (Agkistrodon contortix), CORT increased more in losers compared to winners one hour after staged fights (Schuett and Grober, 2000; Schuett et al., 1996). Furthermore, CORT positively correlated with female $S$. undulatus home range overlap (Haenel et al., 2003a). In male S. undulatus, plasma concentrations of CORT and T peak during the breeding season (John-Alder et al., 2009). In Phrynosoma cornutum, CORT levels tended to be higher during the breeding season (Wack et al., 2007). In reptiles and amphibians, slight elevations in CORT appear to influence reproduction behavior and/or physiology by mobilizing energy reserves (Moore and 
Jessop, 2003). Therefore, it seems possible that CORT affects spatial ecology in $S$.

occidentalis as spatial ecology in this species is related to reproduction. Unfortunately, we neither controlled for nor measured CORT in our subjects. Investigating the effect of the potential interaction between CORT and $\mathrm{T}$ on home range size would be an interesting next step.

Other potential endocrine regulators of territorial behavior may include the nonapeptides arginine vasopression (AVP) and mesotocin, the reptilian oxytocin homolog. AVP populations in the brain were activated after males were exposed to intrasexual agnostic behaviors (Kabelik et al., 2013). Mesotocin increased in response to courtship frequency, but not agnostic behaviors (Kabelik et al., 2015). Therefore, perhaps $\mathrm{T}$ initiates territorial behaviors and one or more of the above hormones interact with $\mathrm{T}$ to influence territoriality after expose to social interactions with conspecifics. Indeed, treatment of $\mathrm{T}$ in white-throated sparrows (Zonotrichia albicollis) caused an increase in AVP receptor and decrease in oxytocin receptor mRNA expression (Grozhik et al., 2014). As stated above, we neither controlled for nor measured these nonapeptides in our subjects.

We found a significant effect of site on home range size. This was likely due to the inherent ecological differences between sites. Although we didn't quantify habitat parameters, there were some apparent differences between sites. Facing southeast, Site 1 had less of a slope and was dominated by mostly grasslands with some shrub and tree vegetation. Site 2 had much more of a slope which faced northeast and was dominated by mostly grasslands. Slope steepness, among many other factors affects soil erosion (Morgan, 2001) which can lead to decreased 
productivity (Pimentel and Kounang, 1998). Perhaps due to the decreased cline at site 1 , soil is not eroded as quickly as site 2 resulting in higher habitat productivity at site 1. If it is the case that site 1 has higher productivity than site 2 , our differences in home range size between sites can be explained by differences in habitat productivity. Decreased habitat productivity results in larger home range sizes in mammals (Herfindal et al., 2005; Relyea et al., 2000). In lizards, Uta stansburiana residing at higher latitudes have larger home range sizes (Scoular et al., 2011). Tinkle (1967) hypothesized that lizards have larger home ranges at higher latitudes due to decreased productivity.

\subsubsection{Body condition}

There seems to be evidence to suggest that $\mathrm{T}$ affects body condition, as $\mathrm{T}$ trended to decrease body mass controlling for SVL at the time of recapture although there were no differences in body condition between $\mathrm{T}$ implanted and blank implanted at the time of surgery. In lizards, prior studies corroborate this relationship; Timplanted male eastern fence and sand lizards lost body mass compared to control individuals that gained body mass (S. undulatus: Klukoski and Nelson, 2001; Lacerta agillis: Olsson et al., 2000). In juvenile male $S$. virgatus and female tree lizards (Urosaurus ornatus), $\mathrm{T}$ caused a slower rate of growth, both in length and mass (Abell, 1998; Hews and Moore, 1995 respectively). T caused a decreased body condition in juvenile male Algerian sand lizards (Civantos, 2002), but not in the adult male Algerian sand lizard (Salvador and Veiga, 2000). Likewise, in red-spotted garter snakes (Thamnophis sirtalis concinnus) nor brown anoles, $\mathrm{T}$ did not correlate with body condition (Moore et al., 2000; Tokarz et al., 1998 respectively). 
In lizards, $\mathrm{T}$ likely indirectly causes a decrease in body condition by facilitating increased energy expenditure by increasing aggressiveness (John-Alder et al., 2009; Civantos, 2002), patrolling (John-Alder et al., 2009), and/or distance traveled between sightings (Olsson et al., 2015). Further, Marler et al. (1995) found male $S$.jarrovi implanted with $\mathrm{T}$ had higher metabolic rates than controls in the field, which was not due to differences in standard metabolic rate measured in the lab. They proposed this increase in metabolic rate was due to increased activity of $\mathrm{T}$ implanted individuals (Marler et al., 1995). In addition to this increase in energy expenditure, $\mathrm{T}$ also caused decreased foraging behaviors in S. jarrovi (Maler and Moore, 1989). This $\mathrm{T}$ dependent increase in energy expenditure and decrease in energy allocation likely explains the decrease in body condition of our $\mathrm{T}$ implanted individuals.

If indeed our $\mathrm{T}$ implanted lizards had lower energy stores (as indicated by decreased body condition), then the lack of a difference among groups in home range sizes could be explained. Body condition positively correlates with numerous spatial ecology factors. In an urban population of house sparrows (Passer domesticus), nutritional condition correlated positively with home range size (Vangestel et al., 2010). Heavier juvenile European roe deer (Capreolus capreolus) had a higher probability of dispersing earlier and farther than lighter conspecifics (Debeffe et al., 2012). In herring (Clupea harengus L.), body condition positively correlated with farther spawning migration (Slotte, 1999). Since we saw an effect of T on body condition, it may be the case that a lack of energy reserves constrained our $\mathrm{T}$ implanted individuals' home ranges. 


\subsubsection{Coloration}

We found that $\mathrm{T}$ affects coloration of $S$. occidentalis by increasing the number of abdominal blue scales. This is consistent with other research that found $\mathrm{T}$ positively affected ventral blue coloration in Sceloporus (S. undulatus: Cox et al., 2005; S. jarrovii: Cox et al., 2008). However, variation in ventral coloration in the abdominal region of adult male $S$. pyrocephalus was not explained by T (Calisi and Hews, 2007). This may be due to the fact that in that particular species, females express similar abdominal ventral coloration (Calisi and Hews, 2007). Therefore, perhaps T doesn't mediate this coloration because it isn't a sexual dimorphic trait.

In numerous other species of lizards, coloration signals intrasexual messages (Fresnillo et al., 2015; Baird et al., 2013; López et al., 2004). For instance, adult aggression was reduced towards juvenile spiny-footed lizards (Acanthodactylus erthrurus) with red coloration (Fresnillo et al., 2015). In Iberian rock lizards (Lacerta monticola), adult males intruders with a lower number of abdominal blue dots received less aggressive behaviors than residents (López et al., 2004). Likewise, smaller adult Algerian sand lizards lacking nuptial coloration expressed in larger, more dominant males received higher agnostic behaviors then when nuptial coloration was experimentally added (Martín and Forsman, 1999). In S. undulatus, there is some evidence to suggest that coloration may signal competitive capabilities to male conspecifics (Langkilde and Boronow, 2010). It seems likely that coloration acts as an intrasexual signal in S. occidentalis that discourages male conspecifics from performing agnostic behaviors towards males with larger ventral blue patches. 
In other animals, coloration is positively related to body condition, which in turn is related to an increase in overall fitness (Trigo and Mota, 2014; Castella et al., 2013; Gawryszewski et al., 2012; Cuervo et al., 2009; López et al., 2004; Barber et al., 2000). Body condition relates to fitness through not only natural selection, but also sexual selection, as female lizards appear to prefer males with higher body conditions. In $U$. stansburiana, females preferred males with higher body condition regardless of male-male contest outcomes (Huyghe et al., 2012). Further, female rock lizards (Iberolacerta cyreni) tongue flicked more often when exposed to male femoral gland secretions containing higher proportions of the lipid oleic acid (Martín and López, 2010). Higher proportions of lipids present in femoral secretions correlate with body condition in I. cyreni (Martín and López, 2010) and Lacerta monticola (López et al., 2006). Female common lizards (Lacerta vivipara) first matings were with males with higher body conditions than rejected males (Fitze et al., 2010). Finally, in a more closely related species, female $S$. undulatus associated more with males in better condition (Swierk et al., 2012). Despite brighter coloration, our T implanted individuals also had lower body condition, which should signal a less fit male. Perhaps we observed these two seemingly contradictory relationships because our Timplanted lizards were displaying a dishonest signal. When survivorship chances decreased, red nuptial coloration actually increased in three-spined sticklebacks (Gasterosteus aculeatus; Candolin, 2000). If this relationship holds true across taxa, our T-implanted individuals could have displayed a dishonest signal as elevated $\mathrm{T}$ causes a marginally significant decrease in survivorship (John-Alder et al., 2009). 


\subsubsection{Minimum number of points for home range measurement}

We found that the minimum number of sightings needed to obtain an accurate home range size for $S$. occidentalis was 5 sightings. However, as evident by the figure graphing each lizard's GIS MCP asymptote, there appears to be some individuals that require more sightings. It is important to note, that the number of individuals with 14 and 15 sightings was four and three respectively. Therefore, the power associated with MCPs with higher number of sightings could simply be too low to be distinguished from smaller MCPs. Individuals with higher number of sightings also had very high variance as one individual had a home range of $400.55 \mathrm{~m}^{2}$ while another only had a home range of $36.96 \mathrm{~m}^{2}$. This may suggest that individuals with larger home range sizes simply require more points to obtain an accurate home range size.

It is interesting to note that the three individuals with 15 sightings or more belonged to the $\mathrm{T}$ implanted group. This observation could be a result of the positive relationship between $\mathrm{T}$ and daily activity levels as evidenced in adult male $S$. jarrovi (Klukowski et al., 2004) and juvenile male S. undulatus (Cox et al., 2005a). Elevating $\mathrm{T}$ could have made our $\mathrm{T}$ implanted lizards more active and thereby more likely to be observed. Investigating the effect of $\mathrm{T}$ on activity levels could be an interesting avenue of spatial ecology research in western fence lizards.

\subsubsection{Comparison of home range size quantification techniques}

We found that MCPs measurement technique resulted in a significantly higher home range measurement compared to a manual measurement of home range. This is 
most likely due to the inherent area calculations of MCPs. MCPs connect the outermost data points convexly to calculate an area, with some enclosed data points existing inside of the polygon. For our manual MCP measurement, we likely included some of those inner data points in our formation of the polygon since measurements were performed in the field without prior mapping out resulting in smaller home range measurements. However, home range measurements from each technique were highly positively correlated and $\mathrm{T}$ did not affect either measurement. Thus, both measurement techniques resulted in similar conclusions, indicating the validity of either measurement technique in future home range experiments for this particular species.

\subsubsection{Conclusions}

Although this study showed that T does not affect home range size in $S$. occidentalis, it would be worth investigating other spatial ecological factors such as territory size and/or movements. T does have an effect on other physiological factors such as body condition and ventral coloration. If females choose males based on coloration, it appears $\mathrm{T}$ has the ability to mediate a dishonest signal, if $\mathrm{T}$ also decreases body condition in S. occidentalis. 


\section{CHAPTER 2: Effect of testosterone on brain regions in free-living western fence lizards}

\subsection{Introduction}

Spatial navigation is necessary for territoriality, mate choice, and acquisition of food resources (Brennan et al., 1990; Shettleworth 1990; and Menzel et al., 2000). In many vertebrate species, male animals tend to have superior spatial navigation abilities to females (Clint et al., 2012). In mammals, the most studied clade, males often outperform females in spatial memory testing (Humans: Woolley et al., 2010; Newhouse et al., 2007; Driscoll et al., 2005; Astur et al., 1998; Moffat et al., 1998; Voles: Kavaliers et al., 1998; Galea et al., 1995; Rats: Faraji et al., 2010; Saucier et al., 2008; Blokland et al., 2006). In reptiles, the only study to date demonstrated differences between the sexes with regards to spatial learning abilities in Eastern water skinks (Eulamprus qouyii). They found males displayed better spatial learning capabilities compared to female conspecifics (Carazo et al., 2014). This difference in spatial navigation capability is likely due to sexual differences with regards to spatial ecology as males tend to have larger home range sizes compared to female conspecifics (Ribeiro et al., 2009; Wone and Beauchamp, 2003; Sheldahl and Martins, 2000; Melville and Swain, 1999).

With increased spatial navigation comes an increased demand for spatial memory, resulting in the growth of brain regions involved with processing spatial memory (Hoshooley et al., 2006; Maguire et al., 2006; Maguire et al., 2000). This increase in volume of these brain regions, or the hippocampus in mammals and birds, is mediated, at least in part, through increases in neurogenesis (Rats: Drapeau et al., 2003; Roof and Havens, 1992; Birds: LaDage et al., 2010). In reptiles, the medial and dorsal cortices (MC 
and DC, respectively) are considered hippocampal homologues and similarly display plasticity with regards to spatial ecology and territory or home range size (Holding et al., 2012; LaDage et al., 2009; Roth et al, 2006. Male cottonmouth snakes (Agkistrodon piscivorus) have larger MC compared to female conspecifics (Roth et al., 2006), presumably due to a sexual dimorphism in spatial movements. In male Northern Pacific rattlesnakes (Crotalus oreganus), short distance translocations caused increased home range size and an increase in MC volume (Holding et al., 2012). In male side-blotched lizards (Uta stainsburiana), non-territorial morphs had smaller DC volumes than morphs holding larger territories (LaDage et al., 2009). Furthermore, territorial male side-blotched lizards had a significantly higher density of doublecortin immunoreactive (DCX-ir) cells compared to non-territorial males in large enclosures (LaDage et al., 2013). DCX is a protein expressed in immature neurons and has been used as a proxy for neurogenesis (Brown et al., 2003).

The ubiquity of adult neurogenesis across vertebrate taxa has been well documented, but the distribution of proliferative regions and survivability of neurons vary greatly (Hastings et al., 2000; Kaslin et al., 2008). Neurogenesis occurring in the reptilian cortical brain regions is of particular interest to allow comparison of the apparent ancestral trait of ventricular proliferation zones among taxa to the relatively newly evolved hippocampal neurogenesis (Urbán and Guillemot, 2014). In all major reptilian taxa, neurons are born on the lateral ventricles $(\mathrm{V})$ and migrate to numerous regions of the brain (Figure 2.1). In the MC, neurons migrate through the inner plexiform layer (IPL) and are integrated into the cell layer (CL); very few cells migrate through the CL into the outer plexiform layer (OPL) (Figure 2.1; Gonález - 
Granero et al., 2011; Pérez-Cañellas et al., 1997). Although very little neurogenesis occurs in the DC (Gonález -Granero et al., 2011), gross morphological changes can occur in this region (LaDage et al., 2009).

One major factor influencing neuroplasticity and neurogenesis is the steroid hormone testosterone (T), which has been demonstrated in rodents (Carbone and Handa, 2013; Galea et al., 2008) and birds (Goodson et al., 2005). One of the best-studied examples is the effect of $\mathrm{T}$ on the seasonal growth of the brain regions involved with singing behavior in songbirds. T primarily controls the increase in song control region volumes, although other factors such as social context and photoperiod can affect growth independently (Balthazart et al., 2010). Furthermore, in some regions, the increase in volume is mediated through changes in neuron survival and neurogenesis. For example, T causes an increase in cell proliferation (Barker et al., 2014), and a decrease in $\mathrm{T}$ decreases neuron number (Thompson et al., 2007).

As $\mathrm{T}$ is responsible for numerous sexual dimorphisms, perhaps it is also responsible for increased spatial navigation abilities in males (Clint et al., 2012). Generally in lizards, territoriality is a male specific trait displayed in response to elevated levels of T (Moore, 1988). Further, T treatment of female Sprague-Dawley rats (Rattus norvegicus) treated increased spatial navigation abilities (Roof and Havens, 1992). However, exogenous $\mathrm{T}$ and estradiol increased spatial memory performance equally in great tits (Parus major; Hodgson et al., 2008). In U. stansburiana, males with higher T levels had larger home range sizes (DeNardo and Sinervo, 1994; Sinervo et al., 2000). Furthermore, territorial male $U$. stansburiana morphs have innately higher T levels compared to non-territorial conspecifics (Sinervo et al., 2000). Since T influences home 
range, we investigated the potential interaction between $\mathrm{T}$ and home range size on cortical brain regions. We hypothesized that $\mathrm{T}$ influences $\mathrm{MC}$ and $\mathrm{DC}$ volumes, possibly mediated through neurogenesis. We predicted that in response to increased T levels, home range size would increase. With this increased demand of spatial memory, the MC and DC volumes would also increase. Therefore we predicted that as T increases, MC and $\mathrm{DC}$ volumes would also increase. Since we expect that $\mathrm{T}$ causes an increase in cortical brain regions, we also expect to see an increase in neurogenesis, as quantified by an increased density of DCX-ir cells in the MC of individuals with higher T levels.

\subsection{Materials and Methods}

\subsubsection{Field experiment procedures}

Adult male western fence lizards (Sceloporus occidentalis) were initially captured by noose from two sites located on the California Polytechnic State University San Luis Obispo campus. Collecting permits were obtained through California Department Fish and Wildlife (permit number SC-11933), and all procedures were completed with approval of the Cal Poly Institutional Animal Care and Use Committee (protocol \#1406). Individuals ( $\mathrm{n}=14)$ from site one $\left(35^{\circ} 19^{\prime} 15^{\prime \prime} \mathrm{N}, 120^{\circ} 40^{\prime} 51^{\prime \prime} \mathrm{W}\right)$ were captured and transported to the lab for bilateral castrations over a three day period from April 7-9, $2014(\mathrm{n}=14)$. Individuals $(\mathrm{n}=10)$ located at site two $\left(35^{\circ} 18^{\prime} 49^{\prime \prime} \mathrm{N}, 120^{\circ} 39^{\prime} 09^{\prime \prime} \mathrm{W}\right)$ were captured from April 23-24, 2014 ( $\mathrm{n}=10)$. Prior to transportation to the lab, all individuals were uniquely marked by toe-clipping and color-coding on the dorsal caudal surface with paint pens for future identification. In addition, snout vent length $(\mathrm{SVL} ;+0.1 \mathrm{~cm})$ and body mass $( \pm 0.1 \mathrm{~g})$, body mass, and initial blood samples were 
taken to measure circulating T levels. Blood samples were collected in the field using heparinized microhematocrit tubes to rupture the retro-orbital sinus within five minutes of being caught. On average, blood samples were collected within $3 \pm 0.22 \mathrm{~min}$ $($ mean \pm standard error of the mean (SEM)) after capture. Blood samples were kept on ice and several hours later transported to the lab, and centrifuged for five minutes at 10,000 rpm. Plasma was collected and stored at $-80^{\circ} \mathrm{C}$ until processing. Twenty-one individuals were captured, marked, and immediately released. These individuals served as unmanipulated controls. Unfortunately we did not measure SVL, body mass, or collect blood samples for these individuals and therefore cannot include them in the repeated measures analysis of covariance (see below).

\subsubsection{Surgical procedure}

Bilateral castration surgeries occurred four to thirty-six hours after initial capture for both castration events. Individuals were subjected to deep anesthesia through inhalation of isoflurane prior to bilateral castration. A bilateral 3- to 5-mm incision was made through the integument and musculature on flank through which the testes were excised by gently teasing connective tissue away from the testes (DeNardo and Licti, 1993). Twelve of these individuals received a T--filled siliastic implant, and the remaining received a blank implant $(n=12)$ before suturing the incisions. Implants were made from five millimeter segments of silastic diffusion tubing (Dow Corning, Clarkesville, TN, U.S.A.: 1.47 inner diameter, $1.96 \mathrm{~mm}$ outer diameter), capped and sealed with silicon caulking (Momentive Performance Materials Inc., Huntersville, NC, U.S.A.), and filled with either three millimeters of crystalline testosterone propionate (Sigma- 
Aldrich, St. Louis, MO, U.S.A.; T implant) or silicon caulking (blank implant). After assembly, $\mathrm{T}$ implants weighted $16.05+0.016 \mathrm{~g}$ while blank implants weighed $16.8 \pm 0.09 \mathrm{~g}$. Subjects were released back to their capture sites after one day to recover from the surgery.

\subsubsection{Home range quantification}

Location of each individual was determined approximately every other day. On average, lizards were sighted $12 \pm 0.9$ times during the study. When a lizard was sighted, the location of that lizard was taken using a TopCon GM2 global positioning system (GPS) unit. Home range was determined by delineation of these points using a $95 \%$ and $100 \%$ minimum convex polygons (MCP) using the software program ARCGIS version 9.2. We found that both the $95 \%$ and $100 \%$ MCPs were identical and therefore only report 100\% MCPs. After 7 weeks, individuals were recaptured over a two-day period from June 10-11, 2014 (Control: $n=4$, Blank implant: $n=4$, T implant: $n=4$ ). Body mass, SVL, and blood samples were immediately retaken at the site of recapture and then transported to California Polytechnic State University San Luis Obispo for sacrifice.

\subsubsection{Sacrifice and immunohistochemisty}

Lizards were sacrificed four to thirty-six hours after re-capture. After the onset of deep anesthesia by inhalation of isoflurane, each lizard was transcardially perfused with a $0.9 \% \mathrm{NaCl}, 0.1 \% \mathrm{NaNO}_{2}, 0.1 \mathrm{M}$ phosphate buffer $(\mathrm{PB})$ wash at $10 \mathrm{~mL} / \mathrm{min}$ for five minutes followed by $4 \%$ paraformaldehyde in $0.1 \mathrm{M} \mathrm{PB}$, with $0.1 \% \mathrm{NaNO}_{2}(\mathrm{PARA})$ for five min. The skulls were cut to partially expose brain tissue and the specimen was stored in PARA. After at least $1 \mathrm{~h}$, the brains were fully dissected out and postfixed in PARA 
for $24 \mathrm{~h}$. Brains were then transferred to a $0.1 \mathrm{M} \mathrm{PB}$ solution for 24 hours prior to embedding in $8 \%$ gelatin. The gelatin was allowed to set for $24 \mathrm{~h}$ at $4^{\circ} \mathrm{C}$, after which the gelatin-embedded brain was placed in PARA. After $24 \mathrm{~h}$, PARA was poured off and the gelatin encased brains were incubated in a 30\% sucrose solution until they sank (approximately $48 \mathrm{~h}$ ) at which point they were placed in dry ice for flash freezing and stored at $-80^{\circ} \mathrm{C}$ until sectioning.

Brains were sectioned into four series of parallel coronal sections using a Bright OTF-5000 cryostat. One series (every fourth section) was directly mounted onto slides, hydrated with mounting solution to flatten sections onto slides, allowed to dry, and stained with cresyl violet. Sections were photographed with a Lecia EZ4 stereo microscope at 20x and stored as digital images for measurement of total telencephalon, MC, DC, and nucleus sphericus (NS) volumes. NS were measured because they have previously been shown to increase with increasing plasma $T$ levels (Kabelik et al., 2008) and therefore would be a good region for comparison. Each brain region volume was traced and the area calculated using Image J (National Institutes of Health, USA). Summed areas were multiplied by section thickness and then by four (the number of sections separating each section) to determine region volumes. The remaining series were stored in cryoprotectant at $-20^{\circ} \mathrm{C}$.

In addition to cresyl violet staining, sections were subjecting to staining against the antibody DCX. In S. occidentalis, DCX is expressed in neurons between two and six weeks after birth (unpublished observations). Free-floating sections (every $8^{\text {th }}$ section) were stained via immunohistochemistry for DCX to quantify immature neurons. Sections were washed with phosphate-buffered saline (PBS) three times for $5 \mathrm{~min}$ prior to 
blocking. Blocking occurred in a solution of 5\% normal horse serum (Vector

Laboratories Inc.) and $0.5 \% \mathrm{H}_{2} \mathrm{O}_{2}$ in PBS plus $0.3 \%$ Triton X-100 (PBST) for one hour. Immediately following blocking, sections were placed in a 1:4,000 anti-DCX (sc-8066, Santa Cruz Biotechnology, Inc.) in PBST and left on a rotator table for $24 \mathrm{~h}$ at room temperature, after which another series of three 5 min washing in PBST occurred. Sections were then subjected to a one hour incubation in 1:100 biotinylated anti-goat secondary antibody (BA-9500, Vector Laboratories Inc.) in PBST. Another series of washes in PBST occurred, followed by incubation in avidin-biotin-perioxidase complex (PK-6100, Vector Laboratories Inc.). Another series of washes in PBST followed, and then sections were incubated in Vector SG Chromagen (SK-4700, Vector Laboratories Inc.) for $5 \mathrm{~min}$. Finally the sections were washed two times for $5 \mathrm{~min}$ in PBS, mounted onto slides and coverslipped. DCX-immnuoreactive (DCX-ir) cells were exhaustively counted in the IPL and CL of the MC using an Olympus BX-60 light microscope. To prevent oversampling, cells were only counted when a clear nuclear void was present (Figure 2.2). The density of DCX-ir cells in each sub-region of the MC was calculated by dividing the cell count by the volume of each sub-region. DCX immunoreactivity was extremely low in the DC (Gonález-Granero et al., 2011), so cells were only counted in the MC.

\subsubsection{Radioimmunoassay}

Radioimmunoassay (RIA) was performed to determine $\mathrm{T}$ levels in lizards prior to surgical treatment and at re-capture for sacrifice. All samples were analyzed in a single assay and $\mathrm{T}$ concentrations were assayed according to a previously established protocol (Moore, 1986; French et al., 2010). Briefly, 30\% ethyl acetate/isooctane extractions were 
performed then separated, dried, and resuspended in $10 \%$ ethyl acetate in isooctane. Testosterone was separated from samples in a $20 \%$ elution of ethyl acetate/isooctane. Samples were collected in vials, dried, and resuspended in PBS buffer. A duplicate aliquot of each sample was assayed for $\mathrm{T}$ levels. The intra-assay coefficient of variation was 0.098 .

\subsubsection{Data analysis}

Data not meeting assumptions for parametric tests were log transformed. To determine if $\mathrm{T}$ affected body condition, we ran a repeated measures analysis of variance (ANOVA) with group, time, and the interaction between group and time as factors. Body condition was determined by finding residuals after regressing log SVL and body mass. We decided to run multiple regressions instead of analysis of covariance to analysis the data due to treatment of $\mathrm{T}$ causing a wide spread of $\mathrm{T}$ levels. We analyzed the effect of body mass controlling for SVL in all recaptured individuals. To determine if $\mathrm{T}$ affected the volume of brain regions or density DCX-ir cells in the $\mathrm{MC}$, predictor variables included plasma $\mathrm{T}$ concentration, home range size, body condition, and total telencephalon (TT) volumes, and site as a cofactor. For the DCXir cells model, we included the same predictor variables, except we did not include total telencephalon volume because we measured DCX-ir cells as a density $\left(\right.$ cells $\left./ \mathrm{mm}^{3}\right)$, therefore brain size was not a relevant variable. We also included the interaction between $\mathrm{T}$ and home range size. All analyses were run in JMP Pro 11 (SAS Institute, Inc.). Body condition, site and the interaction between $\mathrm{T}$ and home range size were non-significant for all models; therefore we removed those variables from all models. 


\subsection{Results}

\subsubsection{Implant verification}

Castration and implantation affected $\mathrm{T}$ levels (Figure 1.1; $\mathrm{F}_{2,11}=10.08$, $\mathrm{p}=0.005$ ). Individuals with $\mathrm{T}$ implants had the highest levels of $\mathrm{T}$ followed by the control group and then the blank implanted group $(\mathrm{p}<0.05)$.

\subsubsection{Body condition}

Comparing T implanted and blank implanted individuals over the course of the experiment, there was no effect of group, time, or group*time on body condition (Figure 1.2; Group: $\mathrm{F}_{1,6}=3.8, \mathrm{p}=0.099$; Time: $\mathrm{F}_{1,6}=0, \mathrm{p}=1$; Time* group: $\mathrm{F}_{1,6}=0.44$, $\mathrm{p}=0.533$ ). Comparing all recaptured lizards, snout-vent length positively correlated with lizard mass (Figure 1.3; $\mathrm{R}^{2}=0.75, \mathrm{~F}_{1,9}=18.14, \mathrm{p}=0.002$ ). After controlling for variation in SVL, the negative relationship between $\mathrm{T}$ and lizard weight approached significance (Figure 1.4; $\mathrm{F}_{1,9}=4.02, \mathrm{p}=0.076$ ).

\subsubsection{Brain regions}

As expected, with increasing TT volume, MC volume increased (Figure 2.3a; $\left.\mathrm{F}_{1,6}=39.49, \mathrm{p}<0.001\right)$. However, there was no effect of $\mathrm{T}$ (Figure 2.4a; $\mathrm{F}_{1,8}=1.57$, $\mathrm{p}=0.245$ ) or home range (Figure $2.5 \mathrm{a} ; \mathrm{F}_{1,8}=0.02, \mathrm{p}=0.885$ ) on $\mathrm{MC}$ volume.

As with the MC, DC volume increased with increasing TT volume (Figure $\left.2.3 \mathrm{~b} ; \mathrm{F}_{1,6}=31.46, \mathrm{p}<0.001\right)$. DC volumes decreased with increasing $\mathrm{T}$ concentrations (Figure 2.4b; $\mathrm{F}_{1,8}=5.41, \mathrm{p}=0.048$ ). Home range size did not affect DC volume (Figure $\left.2.5 \mathrm{~b} ; \mathrm{F}_{1,8}=1.47, \mathrm{p}=0.259\right)$. 
No variables significantly predicted the density of DCX-ir cells in the cell layer (CL) or inner plexiform layer (IPL) of the MC (Figure 2.6; CL: $\mathrm{F}_{2,9}=0.353$, $\mathrm{p}=0.712 ;$ IPL: $\left.\mathrm{F}_{2,9}=0.1, \mathrm{p}=0.907\right)$.

As expected NS volume increased with TT volume (Figure 2.7a; $F_{1,9}=8.54$, $\mathrm{p}=0.017$ ). Surprisingly, $\mathrm{T}$ did not affect NS volume (Figure $2.8 \mathrm{~b} ; \mathrm{F}_{1,9}=0.03, \mathrm{p}=0.875$ ).

\subsection{Discussion}

We did not find evidence to suggest that variation in $\mathrm{MC}$ volume or neurogenesis is affected by short-term elevation of circulating $\mathrm{T}$ concentration or relates to individual variation in home range size. However, DC volume is significantly negatively affected by T. Our results are inconsistent with previous research demonstrating that space use affects cortical brain volumes in lizards (LaDage et al., 2009). We also did not find evidence that neurogenesis, or at least immature neuron density, is affected by $\mathrm{T}$ or home range size, which is inconsistent with prior research on side-blotched lizards (LaDage et al., 2013). Surprisingly, we did not find evidence to suggest that T affects NS volume, which is not consistent with prior research in lizards (Kabelik et al., 2008).

\subsubsection{Testosterone and neuroplasticity}

Contrary to our predictions, in this experiment $\mathrm{T}$ negatively affected DC volume and did not affect MC volume. Further, T did not affect neurogenesis in the $\mathrm{MC}$ of these lizards. In numerous other studies in a variety of vertebrates, there is significant evidence to suggest that $\mathrm{T}$ affects the morphology of brain regions involved in regulating reproductive behaviors, generally by increasing neurogenesis 
within these regions or increasing the size of reproductive related brain regions. In tree lizards, $\mathrm{T}$ caused an increase in amygdala and nucleus sphericus volumes (Kabelik et al., 2008). It is well established that in songbirds, $\mathrm{T}$ increases the size of the song control regions and neurogenesis in the $\mathrm{HVC}$, a song related region in the brain (Barker et al., 2014;, Balthazart et al., 2010; Dittrich et al., 2014; Rasika et al., 1994). Moreover, $\mathrm{T}$ affects brain regions not directly related to reproduction, such as the hippocampus, again generally increasing size or neurogenesis; for example, in mammals, $\mathrm{T}$ and estradiol increase hippocampal neurogenesis (Galea et al., 2008) and gonadectomy decreased cell proliferation in the dentate gyrus (Spritzer et al., 2011; Wainwright et al., 2011). Castrated males with T replacement displayed higher cell proliferation in one region of the subventricular zone than castrated males, but had equal cell proliferation compared to sham operated males (Farinetti et al., 2015). Spine synapse density in the dentate gyrus decreased in castrated males compared to controls (Mendell et al., 2014). Androgen receptors in the hippocampus were also influenced by $\mathrm{T}$ as castration decreased the number of immunoreactive androgen receptors. In addition, injecting castrated males recused the overall number of androgen receptors in the hippocampus (Xiao and Jordan, 2002).

However, T may have different effects on neuroplasticity depending on seasonal or ontogenetic factors. In male house finches (Haemorhous mexicanus), $\mathrm{T}$ treatment in the fall does not increase the size of the song control regions (Strand et al., 2008). In adolescent male rhesus macaques (Macaca mulatta), gonadectomy increases neuron survival and neurogenesis in the hippocampus (Allen et al., 2014). In Japanese quail (Coturnix japonica), ontogeny affects the activity of aromatase and 
tyrosine hydroxylase in the preoptic area of the brain (Balthazart et al., 2000).

Although to date there are no studies investigating potential ontogenetic effects on the reptilian brain, some studies found ontogenetic effects on behaviors, including locomotion (Irschick et al., 2000), exploration (Bajer et al., 2015), and antipredation tactics (Landová et al., 2013). This may suggest ontogenetic effects can occur in the reptilian brain. As there seems to be ontogeny effects on behavior and neuroplasticity in other species that exist beyond adulthood, potentially, the age of the adult lizards in our study could be a confounding variable.

Another variable to consider is that lizards with elevated T may have also have been in a more "stressed" condition. Male lizards with elevated T levels display an increase in aggressive behaviors (Urosaurus ornatus: Weiss and Moore, 2004; Paroedura picta: Golinski et al., 2014). Aggressive behaviors correlated with elevated CORT levels in eastern water dragons, Physignathus lesueurii (Baird et al., 2014). In mammals, elevated CORT decreases neurogenesis (Cameron and Gould, 1994; McEwen 1996; Mirescu 2006). If these conditions hold true in S. occidentalis, perhaps we saw a decrease in $\mathrm{DC}$ volumes of $\mathrm{T}$ implanted individuals due to elevated and sustained levels of CORT in response to increased aggressive interactions ultimately caused by our dose of T. Indeed, systematic administration of CORT decreases brain-derived neurotrophic factor (BDNF), a growth factor positively affecting neuronal development and survival, in the hippocampus of mammals (Suri and Vaidya, 2013). Furthermore, CORT implants decreased HVC volume in male song sparrows (Melospiza melodia; Newman et al., 2010). 
In light of the surprising lack of evidence for an effect of T on the NS and the negative relationship between $\mathrm{T}$ and $\mathrm{DC}$ volume, it seems likely we inadvertently introduced a confounding variable in our experimental design. The aim of this study was to determine the effect of physiologically relevant doses of $\mathrm{T}$ on home range size and neuroplasticity; however, our treatment elevated circulating $\mathrm{T}$ concentrations to pharmacological levels. Our T implanted individuals averaged plasma T levels of $75.89 \pm 22.17 \mathrm{ng} / \mathrm{mL}$ while our control individuals had plasma T levels of $8.28 \pm 4.18$ $\mathrm{ng} / \mathrm{mL}$. Another study on S. occidentalis reported T levels as $21.1 \pm 2.8 \mathrm{ng} / \mathrm{mL}$ (Pollock et al., 2012). Other studies on Sceloporus report breeding T levels of $7.7 \pm 2.8$ $\mathrm{ng} / \mathrm{mL}$ in S. undulatus (Klukowski et al., 2001) and $46.4 \pm 5.9 \mathrm{ng} / \mathrm{mL}$ in $S$. yarrowii (Cox et al., 2008). Our implants were constructed following the methods of a previous researcher who obtained physiologically relevant doses (Pollock et al., 2012). Nevertheless, the pharmacological doses that we achieved could have impacted our lizards adversely. There seems to be evidence to suggest that $\mathrm{T}$ affects body condition in our subjects, as T trended to decrease body mass controlling for SVL at the time of recapture although there were no significant differences in body condition between $\mathrm{T}$ implanted and blank implanted at the time of surgery. This trend is in line with previous research suggesting $\mathrm{T}$ adversely affects body condition in $S$. undulatus that were subjected to elevated $\mathrm{T}$ levels for approximately the same duration as our study (Klukowski and Nelson, 2001) and also in numerous taxa (lizards: Olsson et al., 2000; birds: Ziegenfus et al., 1991; frogs: Narayan et al., 2013; and humans: Traish, 2014). In lizards, $\mathrm{T}$ likely indirectly causes a decrease in body condition by facilitating increased energy expenditure by increasing aggressiveness (John-Alder et al., 2009; 
Civantos, 2002), patrolling (John-Alder et al., 2009), and/or distance traveled between sightings (Olsson et al., 2015). Further, Marler et al. (1995) found male $S$. jarrovi implanted with $\mathrm{T}$ had higher metabolic rates than controls in the field, which was not due to differences in standard metabolic rate measured in the lab. They proposed this increase in metabolic rate was due to increased activity of $\mathrm{T}$ implanted individuals (Marler et al., 1995). In addition to this increase in energy expenditure, $\mathrm{T}$ also caused decreased foraging behaviors in S. jarrovi (Maler and Moore, 1989). This T dependent increase in energy expenditure and decrease in energy allocation likely explains the possible decrease in body condition of our $\mathrm{T}$ implanted individuals. With this decrease in body condition, perhaps individuals only have enough energy to perform essential processes in the body which could explain our results if increasing or even maintaining certain brain regions such as the DC volume is not considered an essential processes with regards to increasing male fitness during the breeding season. With pharmacological levels of $\mathrm{T}$, it seems very likely that associated metabolites such as dihydrotestosterone (DHT) and estradiol (E2) potentially confounded our results as both affect neurogenesis in mammals and birds (Galea, 2008; Hidalgo et al., 1995). In male rats, T and E2, but not DHT increased cell proliferation (Farinetti et al., 2015; Galea, 2008). In male rats, DHT increased cell survival (Hamson et al., 2013; Galea, 2008). In female rodents, E2 initially increased cell proliferation in the hippocampus, but then subsequently decreased cell proliferation after 48 hours of exposure. However, after three days of E2 exposure, neurogenesis was not affected (Galea, 2008). Adult female canaries had increased adult neurogenesis in the HVC when exposed to E2 (Hidalgo et al., 1995). These lines 
of evidence certainly suggest that $\mathrm{T}$ metabolites affect neurogenesis, which we did not account for. However, these studies employed ecologically relevant exogenous hormone replacement. In light of our results, it seems likely that pharmacological levels of T metabolites, which were probably present in our study, may affect neurogenesis differently than ecologically relevant doses.

Pharmacological doses of T may affect neuroplasticity and/or neurogenesis differently due to a decrease in body condition. In juvenile song sparrows, food limitation prior to song learning caused smaller HVC volume (MacDonald et al., 2006). Presumably, food-restricted individuals had lower body conditions and thus had less energy available for increasing HVC volume compared to controls. Nestling canaries infected with parasites also displayed a decrease in HVC volumes compared to controls (Spencer et al., 2005). Parasitism correlates with a decrease in fat scores in numerous species of birds (Garvin et al., 2006). This suggests that, at the very least in juvenile birds, body condition has the potential to affect brain region volumes, although this relationship must be tested empirically. This relationship as yet to be tested in reptiles, but if it holds true in not only adult birds but also across taxa, we potentially and inadvertently introduced body condition as a confounding variable through pharmacological doses of $\mathrm{T}$.

\subsubsection{Spatial ecology and neuroplasticity}

We did not find significant relationships between cortical brain regions and home range size in S. occidentalis. However, in side-blotched lizards, this relationship has been demonstrated and is mediated through an increase in neurogenesis in the MC (LaDage et al., 2009; LaDage et al., 2013). The minimum number of sightings needed 
to obtain an accurate home range measurement is roughly five for this species (see Chapter 1). Only one lizard of the 12 sacrificed lizards had fewer than 5 sightings, so it seems unlikely that home ranges were underestimated.

Body condition may have shrouded this relationship. With decreased body condition, individuals would likely be in a negative energy balance and therefore be less likely to be able to maintain a larger home range size. Indeed body condition correlates positively with dispersal distance in Roe deer (Capreolus capreolus) (Debeffe et al., 2012), migratory distance in spawning herring (Clupea pallasii) (Slotte, 1999), and home range size in urban house sparrows (Passer domesticus) (Vangestel et al. 2008). The negative effect of $\mathrm{T}$ and body condition could explain the lack of correlation of home range and cortical brain volume ranges. Perhaps our lizards were constrained by a lack of energy availability, observed as decreased body condition due to increased $\mathrm{T}$, which inhibited attainment of a 'maximum' home range size.

Perhaps T may not mediate the relationship between spatial ecology and related regions of the brain. Despite mammals displaying ubiquitous spatial memory sexual dimorphisms, evidenced through differences in hippocampus volumes, this relationship remains a bit more equivocal in other taxa. In great tits, brown-headed cowbirds (Molothrus ater), and shiny cowbirds (Molothrus bonariensis), females have enhanced spatial memory compared to male conspecifics, and this is reflected in larger hippocampus volumes in females (Brodin and Urhan, 2015; Guigueno et al., 2014; Reboreda et al., 1996). However, in rufous hummingbirds (Selasphorus rufus) and other species of cowbirds, no sexual dimorphism in hippocampus volume exists 
(Reboreda et al., 1996 and Healy and Hurly, 1995). In shiny cowbirds, females are the sole locators of broods to parasitize; whereas in other cowbird species, either both parents or just the male searches for potential broods to parasitize. This suggests that spatial demand, regardless of sex steroid hormones, is the main facilitator of neuroplasticity in spatial related brain regions. With the lack of difference in home range sizes in our lizards, it follows that there would be no difference in their cortical volumes or neurogenesis.

\subsubsection{Conclusions}

In conclusion, $\mathrm{T}$ negatively affects the $\mathrm{DC}$, potentially mediated through a decrease in body condition. Perhaps T did not affect MC to the same extent as the DC due to the MC displaying less intrinsic plasticity; in side-blotched lizards, the MC does not display plasticity to spatial demands (LaDage et al., 2009; LaDage et al., 2013). In S. occidentalis, T - at least at pharmacological doses - does not appear to modulate the positive correlation between home range and DC observed in other lizard species. However, one major caveat with our study was the low sample size across groups. It may be the case that this system does adhere to previous research with regards to spatial demand increasing spatial related regions in the brain, but perhaps we were unable to discern this difference due to low statistical power. Although not in the direction we predicted, this evidence does support the hypothesis that $\mathrm{T}$ influences neuroanatomy. However, this influence is not mediated through an effect on neurogenesis. It seems plausible that $\mathrm{T}$ influences other parameters, such as body condition, which in turn may affect behavior and neuroplasticity. 


\section{BIBLIOGRAPHY}

Abell, A.J. 1999. Male-female spacing patterns in the lizard, Sceloporus virgatus. Amphibia-Reptilia 20: 185-194.

Abell, A.J. 1998. The effect of exogenous testosterone on growth and secondary sexual character development in juveniles of Sceloporus virgatus. Herpetologica 54(4): 553-543.

Akanmu, M.A. and K. Honda. 2005. Selective stimulation of orexin receptor type 2 promotes wakefulness in freely behaving rats. Brain Res. 1048(1-2): 138-145.

Allen, K.M., S.J. Fung, D.A. Rothmond, P.L. Noble, and C. S. Weickert. 2014. Gonadectomy increases neurogenesis in the male adolescent Rhesus macque hippocampus. Hippocampus 24: 225-238.

Anderson, D.P., J.D. Forester, M.G. Turner, J.L. Frair, E.H. Merrill, D. Fortin, J.S. Mao, and M.S. Boyce. 2005. Factors influencing female home range sizes in elk (Cervus elaphus) in North American landscapes. Landscape Ecol. 20: 257-271.

Astur, R.S., M.L. Ortiz, and R.J. Sutherland. 1998. A characterization of performance by men and women in a virtual Morris water task: A large and reliable sex difference. Behav. Brain Res. 93: 185-190.

Baird, T.A., M.B. Lovern, and R. Shine. 2014. Heightened aggression and winning contests increase corticosterone but decreased testosterone in male Australian water dragons. Horm. Behav. 66(2): 393-400.

Baird, T.A., T.D. Baird, R. Shine. 2013. Showing red: male coloration signals samesex rivals in an Australian water dragon. Herpetologica 69(4): 436-444.

Baird, T.A., C.L. Sloan, and D.K. Timanus. 2001. Intra- and inter-seasonal variation in the socio-spatial behavior of adult male collared lizards, Crotaphytus collaris (Reptilia, Crotaphytidae). Ethology 107(1): 15-32.

Balthazart, J., T.D. Charlier, J.M. Barker, T. Yamamura, and G.F Ball. 2010. Sex steroid-induced neuroplasticity and behavioral activation in birds. Eur. J. Neurosci. 32: 2116-2132.

Bajer, K., O. Molnár, J. Török, G. Herczeg. 2010. Female European green lizards (Lacerta viridis) prefer males with high ultraviolet throat reflectance. Behav. Ecol. Sociobiol. 64: 2007-2014.

Bajer, K., G. Horváth, O. Molnár, J. Török, L.Z. Garamszegi, and G. Herczeg. 2015. European green lizard (Lacerta viridis) personalities: Linking behavioral types to ecologically relevant traits at different ontogenetic stages. Behav. Process. 111: 67-74. 
Balthazart, J., O. Tlemçani, N. Harada, and M. Baillien. 2000. Ontogeny of aromatase and tyrosine hydroxylase activity and of aromatase-immunoreactive cells in the preoptic are of male and female Japanese quail. J. Neuroendocrinol. 12: 853866.

Barber, I., S.A. Arnott, V.A. Braithwaite, J. Andrew, W. Mullen, and F.A. Huntingford. 2000. Carotenoid-based sexual coloration and body condition in nesting male sticklebacks. J. Fish Biol. 57: 777-790.

Barker, J.M., G.F. Ball, and J. Balthazart. 2014. Anatomically discrete sex differences and enhancement by testosterone of cell proliferation in the telencephalic ventricular zone of the adult canary brain. J. Chem. Neuroanat. 55: 1-8.

Blokland, A., K. Rutten and J. Prickaerts. 2006. Analysis of spatial orientation strategies of male and female Wistar rats in a Morris water escape task. Behav. Brain Res. 171: 216-224.

Brennan, P., H. Kaba, and E.B. Keverne. 1990. Olfactory recognition: a simple memory system. Science 250: 1223-1226.

Brodin, A. and A.U. Urhan. 2015. Sex differences in learning ability in a common songbird, the great tit - females are better observational learners than males. Behav. Ecol. Sociobiol. 69: 237-241.

Brown, J.P., S. Couillard-Després, C.M. Cooper-Kuhn, J. Winkler, L. Aigner, and H.G. Kuhn. 2003. Transiet expression of doublecortin during adult neurogenesis. J. Comp. Neurol.467(1): 1-10.

Calisi, R.M. and D. K. Hews. 2007. Steroid correlates of multiple color traits in the spiny lizard, Sceloporus pyrocephalus. J. Comp Physiol. B. 177: 641-654.

Candolin, U. 2000. Increased signaling effort when survival prospects decrease: malemale competition ensures honesty. Anim. Behav. 60: 417-422.

Carazo, P., D.W.A. Noble, D. Chandrasoma, and M.J. Whiting. 2014. Sex and boldness explain individual differences in spatial learning in lizards. P. R. Soc. B. 281: 20133275 .

Carbone, D.L. and R.J. Handa. 2013. Sex and stress hormone influences on the expression and activity of brain-derived neurotrophic factor. Neuroscience 239: 295-303.

Castella, B., J. Golay, J.-C. Monney, P. Golay, K. Mebert, and S. Dubey. 2013. Melanism, body condition and elevational distribution in the asp viper. $J$. Zool. 290: 273-280. 
Civantos, E. 2000. Home-range ecology, aggressive behaviour, and survival in juvenile lizards, Psammodronus algirus. Can. J. Zool. 78: 1681-1685.

Civantos, E., 2002. Testosterone supplementation in juvenile Psammodromus algirus lizards: consequences for aggressiveness and body growth. Acta Ethol. 4: 91-95.

Clint, E.K., E. Sober, T. Garland Jr., and J.S Rhodes. 2012. Male superiority in spatial navigation: Adaptation or side effect? Q. Rev. Biol. 87(4): 290-313.

Cohen, R.E., and J. Wade. 2010. Testosterone selectively affects aromatase and $5 \alpha-$ reductase activities in the green anole lizard brain. Gen. Comp. Endocr. 166: 128-133.

Couillard-Despres, S., B. Winner, S. Schaubeck, R. Aigner, M. Vroemen, N. Weidner, U. Bogdahn, J. Winkler, H. Kuhn, and L. Aigner. 2005. Doublecortin expression levels in adult brain reflect neurogenesis. Eur. J. Neurosci. 21(1): 114.

Cox, R.M., V. Zilberman, and H.B. John-Alder. 2008. Testosterone stimulates the expression of social color signal in Yarrow's spiny lizard, Sceloporus jarrovii. J.Exp. Zool. 309A: 505-514.

Cox, R.M., S.L. Skelly, and H.B. John-Alder. 2005a. Testosterone inhibits growth in juvenile male eastern fence lizards (Sceloporus undulatus): implications for energy allocation and sexual size dimorphism. Physiol. Biochem. Zool. 78: 531-545.

Cox, R.M. S.L. Skelly, A. Leo, and H. B. John-Alder. 2005b. Testosterone regulates sexually dimorphic coloration in the eastern fence lizard, Sceloporus undulatus. Copeia 3: 597-608.

Cuervo, J.J., M.J. Palacios, A. Barbosa. 2009. Beak coloration as a possible sexual ornament in gentoo penguins: sexual dichromatism and relationship to body condition. Polar Biol. 32: 1305-1314.

Davis, J. and R.G. Ford. 1983. Home range in the western fence lizard (Sceloporus occidentalis occidentalis). Copeia 4: 933-940.

Debeffe, L., N. Morellet, B. Cargnelutti, B. Lourtet, R. Bon, J-M. Gaillard, and A.J. Mark Hewison. 2012. Condition-dependent natal dispersal in a large herbivore: heavier animals show a greater propensity to disperse and travel further. $J$. Anim. Ecol. 81: 1327-1337.

DeNardo, D.F. and p. Licht. 1993. Effects of corticosterone on social behavior of males lizards. Horm. Behav. 27: 184-199. 
DeNardo, D.F. and Sinervo B. 1994. Effects of steroid hormone interaction on activity and home range size of male lizards. Horm. Behav. 28: 273-287.

Dittrich, F., C. Ramenda, D. Grillitsch, C. Frankl-Vilches, M. Ko, M. Hertel, W. Goymann, A. ter Maat, and M. Gahr. 2014. Regulatory mechanisms of testosterone-stimulated song in the sensorimotor nucleus HVC of female songbirds. BMC Neurosci. 15: 128-144.

Domínguez, L., R. Morona, A. Joven, A. González, and J.M. López. 2010. Immunohistochemical localization of orexins (hypocretins) in the brain of reptiles and its relation to monoaminergic systems. J. Chem. Neuroanat. 39(1): 20-34.

Drapeau, E., W. Mayo, C. Aurosseau, M. Le Moal, P.V. Piazza, and D.N. Abrous. 2003. Spatial memory performances of aged rats in the water maze predict levels of hippocampal neurogenesis. PNAS 100(24): 14385-14390.

Driscoll, I., D.A. Hamilton, R.A. Yeo, W.M. Brooks, and R.J. Sutherland. 2005. Virtual navigation in humans: the impact of age, sex, and hormones on place learning. Horm. Behav. 47: 326-335.

Faraji, J., G.A. Metz, and R.J. Sutherland. 2010. Characterization of spatial performance in male and female Long..Evans rats by means of the Morris water task and the ziggurat task. Brain Res. Bull. 81: 164-172.

Farinetti, A., S. Tomasi, B. Foglio, A. Ferraris, G. Ponti, S. Gotti, P. Peretto, and G.C. Panzica. 2015. Testosterone and estradiol differentially affect cell proliferation in the subventricular zone of young adult gonadectomized male and female rats. Neuroscience 286: 162-170.

Fisher, D.O. 2000. Effects of vegetation structure, food and shelter on the home rnage and habitat use of an endangered wallaby. J. Appl. Ecol.37: 660-671.

Fresnillo, B., J. Belliure, and J.J. Cuervo. 2015. Red coloration in juvenile spinyfooted lizards, Acanthodactylus erythrurus, reduces adult aggression. Anim. Behav. 102: 59-67.

French, S.S., D.F. DeNardo, T.J. Greives, C.R. Strand, and G.E. Demas. 2010. Human disturbance alters endocrie and immune function in the Galapagos marine iguana (Amblyrhynchus cristatus). Horm. Behav. 58(5): 792-799.

Galea, L.A.M. 2008. Gonadal hormone modulation of neurogenesis in the dentate gyrus of adult male and female rodents. Brain Res. Rev. 2008: 332-341. 
Galea, L.A.M., K.A. Uban, J.R. Epp, S. Brummelte, C.K. Barha, W.L. Wilson, S.E. Leiblich, and J.L. Pawluski. 2008. Endocrine regulation of cognition and neuroplasticity: our pursuit to unveil the complex interaction between hormones, the brain, and behavior. Can.J. Exp. Psychol. 62(4): 247-260.

Galea, L.A.M., M. Kavaliers, and K.P. Ossenkopp. 1996. Sexually dimorphic spatial learning in meadow voles Microtus pennsylvaicus and deer mice Peromyscus maniculatus. J. Exp. Biol. 199: 195-200.

Galea, L.A.M., M. Kavaliers, K.P. Ossenkopp, E. Hampson. 1995. Gondal hormone levels and spatial learning performances in the Morris water maze in male and female meadow voles, Microtus pennsylvaicus. Horm. Behav. 29(1):106 $\cdots 125$.

Garvin, M.C., C.C Szell, and F.R. Moore. 2006. Blood parasites of NearcticNeotropical migrant passerine birds during spring trans-gulf migration: impact on host body condition. J. Parasitol. 92(5): 990-996.

Gawryszewski, F.M., A.L. Llandres, and M.E. Herberstein. 2011. Relationship between colouration and body condition in a crab spider that lures pollinators. $J$. Exp. Biol. 215: 1128-1136.

Golinski, A., K. Kubicka, H. John-Alder, L. Kratochvil. 2014. Elevated testosterone is required for male copulatory behavior and aggression in Madagascar ground gecko (Paroedura picta). Gen. Comp. Endocrinol. 205: 133-141.

González-Granero, S., M. Lezameta, and J.M. García-Verdugo. 2011. Adult neurogenesis in reptiles. Neurogenesis in the Adult Brain I: Neurobiology Springer 169-189.

Grozhik, A.V., P. Horoszko, B.M. Horton, Y. Hu, D.A. Voisin, and D.L. Maney. 2014. Hormonal regulation of vasotocin receptor mRNA in a seasonally breeding songbird. Horm. Behav. 65: 254-263.

Grubb, T.C. 1989. Ptilochronology - feather growth bars as indicators if nutritional status. Auk 106: 314-320.

Guigueno, M.F., D.A. Snow, S.A. MacDougall-Shackleton, and D.F. Sherry. 2014. Female cowbirds have more accurate spatial memory than males. Biol. Lett. 10: 1-4.

Haenel, G.J., L.C. Smith, and H.B. John-Alder. 2003a. Home-range analysis in Sceloporus undulatus. II. A test of spatial relationships and reproductive success. Copeia 2003(1): 113-123.

Haenel, G.J. L.C. Smith, and H.B. John-Alder. 2003b. Home-range analysis in Sceloporus undulatus (eastern fence lizard). I. Spacing patterns and the context of territorial behavior. Copeia 1: 99-112. 
Hall, Z.J., and S.A. MacDougall-Shackleton. 2012. Influence of testosterone metabolites on song-control system neuroplasticity during photostimulation in adult European starlings (Sturnus vulgaris). PLOS One 7(7): e40060. doi: 10.1371/journal.pone.0040060.

Halliday, W.D., J.E. Paterson, L.D. Patterson, S.J. Cooke, and G. Blouin-Demers. 2014. Testosterone, body size, and sexual signals predict parasite load in Yarrow's spiny lizards. Can. J. Zool. 92: 1075-1082.

Hanley, K.A. and J.A. Stamps. 2002. Does corticosterone mediate bidirectional interactions between social behavior and blood parasites in the juvenile black iguana, Ctenosaura similis? Anim. Behav. 63: 311-322.

Hastings, N.B., P. Tanapat, and E. Gould. 2000. Comparative views of adult neurogenesis. The Neuroscientist 6(5): 315-325.

Healy, S.D. and T.A. Hurly. 1995. Spatial memory in rufous hummingbirds (Selasphorus rufus): A field test. Anim. Learn. Behav. 23(1): 63-68.

Herfindal, I., J.D.C. Linnnell, J. Odden, E.B. Nilsen, and R. Andersen. 2005. Prey density, environmental productivity and home-range size in the Eurasian lynx (Lynx lynx). J. Zool. Lond. 265: 63-71.

Hews, D.K. and M.C. Moore. 1995. Influence of androgens on differentiation of secondary sex characters in tree lizards, Urosaurus ornatus. Gen. Comp. Endocrinol. 97(1): 86-102.

Hidalgo, A., K. Barami, K. Iversen, and S.A. Goldman. 1995. Estrogens and nonestrogeneic ovarian influences combine to promote the recruitment and decrease the turnover of new neurons in the adult female canary brain. J. Neurobiol. 27: 470-487.

Hodgson, Z.G., S.L. Meddle, J.K. Christians, T.S. Sperry, and S.D. Healy. 2008. Influence of sex steroid hormones on spatial memory in a songbird. J. Comp. Physiol. A 194(11): 963-969.

Holding, M.L., J.A. Frazier, E.N. Taylor, and C.R. Strand. 2012 . Experimentally altered navigational demands induce changes in the cortical forebrain of free-ranging Northern Pacific rattlesnakes (Crotalus o. oreganus). Brain Behav. Evolut. 79: 144-154.

Hoshooley, J.S., L.S. Phillmore, D.F. Sherry, and S.A. MacDougall-Shackleton. 2007. Annual cycle of the black-capped chickadee: Seasonality of food-storing and the hippocampus. Brain Behav. Evolut. 69: 161-168. 
Huyghe, K., B. Vanhooydonck, A. Herrel, A. Tadic, R. Van Damme. 2012. Female lizards ignore the sweet scent of success: male characteristics implicated in female mate preference. Zool. 115: 217-222.

Irschick, D.J. T.E. Macrini, S. Koruba, and J. Forman. 2000. Ontogenetic differences in morphology, habitat use, behavior, and sprinting capacity in two West Indian Anolis lizards. J. Herp. 34(3): 444-451.

John-Alder, H.B., R.M. Cox, G.J. Haenel, and L.C. Smith. 2009. Hormones, performance and fitness: Natural history and endocrine experiments on a lizard (Sceloporus undulatus). Integr. Comp. Biol. 49(4): 393-407.

Kabelik, D., S.L. Weiss, and M.C. Moore. 2008. Steroid hormones alter neuroanatomy and aggression independently in the tree lizard. Physiol. Behav. 93(3): 492-501.

Kabelik, D., V.C. Alix, E.R. Burford, and L.J. Singh. 2013. Aggression- and sex-induced neural activity across vasotocin populations in the brown anole. Horm. Behav. 63: 437-446.

Knapp, R. and M.C. Moore. 1995. Hormonal responses to aggression vary in different types of agonistic encounters in male tree lizards, Urosaurus ornatus. Horm. Behav. 29: 85-105.

Kaslin, J., J. Ganz, and M. Brand. 2008. Proliferation, neurogenesis, and regeneration in the non-mammalian vertebrate brain. Phil. Trans. R. Soc. B 363: 101-122.

Kavaliers, M., K.P. Ossenkopp, L.A.M. Galea, and Bryan Kolb. 1998. Sex differences in spatial learning and prefrontal and parietal cortical dendritic morphology in the meadow vole, Microtus pennsylvanicus. Brain Res. 810: 41-47.

Kerr, G.D. and C.M. Bull. 2006. Exclusive core areas in overlapping ranges of the sleepy lizard, Tiliqua rugose. Behav Ecol. 17: 380-391.

Ketterson, E.D., V. Nolan Jr., L. Wolf, C. Ziegenfus, A.M. Dufty Jr., G.F. Ball, and T.S. Johnson. 1991. Testosterone and avian life histories: The effect of experimentally elevated testosterone on corticosterone and body mass in dark-eyed juncos. Horm. Behav. 25: 489-503.

Klukowski, M., B. Ackerson, and C.E. Nelson. 2004. Testosterone and daily activity period in laboratory-housed mountain spiny lizards, Sceloporus jarrovi.J. Herp. 38(1): 120-124. 
Klukowski, M. and C.E. Nelson. 2001. Ectoparasite loads in free-ranging northern fence lizards, Sceloporus undulatus hyacinthinus: Effects of testosterone and sex. Behav. Ecol. Sociobiol. 48(4): 289-295.

Klukowski, M. and C.E. Nelson. The challenge hypothesis and seasonal changes in aggression and steroids in male northern fence lizards (Sceloporus undulatus hyacinthinus). Horm. Behav. 33: 197-204.

LaDage, L.D., B.J Riggs, B. Sinervo, and V.V. Pravosudov. 2009. Dorsal cortex volume in male side-blotched lizards, Uta stansburiana, is associated with different space use strategies. Anim. Behav. 78: 91-96.

LaDage, L.D., T.C. Roth II, R.A. Fox, and V.V. Pravosudov. 2010. Ecologically relevant spatial memory use modulates hippocampal neurogenesis. $P . R$. Soc. B. 227(1684): 1071-1079.

LaDage, L.D., R.M. Maged, M.V. Forney, B. Sinvervo, T.C. Roth II, and V.V. Pravosudov. 2013. Interaction between territoriality, spatial environment, and hippocampal neurogenesis in male side-blotched lizards. Behav. Neurosci. 127(4): 555-565.

Landová, E., J. Jancúchová, V. Musilová, S. Kadochová, and D. Frynta. 2013. Ontogenetic switch between alternative antipedatory strategies in the leopard gecko (Eublepharis macularius). Behav. Ecol. Sociobiol. 67: 1113-1122.

Langkilde, T., and K.E. Boronow. 2010. Color as a signal: the relationship between coloration and morphology in male eastern fence lizards, Sceloporus undulatus. J. Herp. 44(2): 261-271.

López, P., J. Martín, and M. Cuadrado. 2004. The role of lateral blue spots in intrasexual relationships between male Iberian rock-lizards, Lacerta monticola. Ethology 110: 543-561.

López, P., L. Amo, and J. Martín. 2006. Reliable signaling by chemical cues of male traits and health state in male lizards, Lacerta monticola.J. Chem.Ecol. 32(2): 473-488.

MacDonald, I.F., B. Kempster, L. Zanette, and S.A. MacDougall-Shackleton. 2006. Early nutritional stress impairs development of a song-control brain region in both male and female juvenile song sparrows (Melospiza melodia) at the onset of song learning. P.R. Soc. B. 273

Maguire, E.A., D.G. Gadian, I.S. Johnsrude, C.D. Good, J. Ashburner, R.S.J. Frackowiak, and C.D. Frith. 2000. Navigation-related structural change in the hippocampi of taxi drivers. PNAS 97(8): 4398-44403. 
Maguire, E.A., K. Woollett, and H.J. Spiers. 2006. London taxi drivers and bus drivers: A structural MRI and neuropsychological analysis. Hippocampus 16(12): 1091-1101.

Marler, C.A., G. Walsberg, M.L. White, and M. Moore. 1995. Increased energy expenditure due to increased territorial defense in male lizards after phenotypic manipulation. Behav. Ecol. Sociobiol. 37: 225-231.

Marler, C.A. and M.C. Moore. 1988. Evolutionary costs of aggression revealed by testosterone manipulations in free-living male lizards. Behav. Ecol. Sociobiol. 23: 21-26.

Marler, C.A. and M.C. Moore. 1989. Time and energy costs of aggression in testosteroneimplanted free-living male mountain spiny lizards (Sceloporus jarrovi). Physiol.Zool. 62: 185-189.

Martín, J. and A. Forsman. Social costs and development of nuptial coloration in male Psammodromus algirus lizards: an experiment. Behav. Ecol. 10(4): 396-400.

Martín, J. and P. López. 2009. Multiple color signals may reveal multiple messages in male Schreiber's green lizards, Lacerta schreiberi. Behav. Ecol. Sociobiol. 63(12): 17431755 .

Martín, J. and P. López. 2010. Condition-dependent pheromone signaling by male rock lizards: more oily scents are more attractive. Chem. Scenses 35: 253-262.

Melville, J. and R. Swain. 1999. Home-range characteristics of an alpine lizard, Niveoscincus microlepidotus (Scincidae), on Mt Wellington, southern Tasmania. Wildlife Res. 26: 263-270.

Menzel, R., R. Brandt, A. Gumbert, B. Komischke, and J. Kunze. 2000. Two spatial memories for honeybee navigation. P. R. Soc. B. 267: 961-968.

Mirescu, C. and E. Gould. 2006. Stress and adult neurogenesis. Hippocampus 16: 233238.

Moffat, S.D., E. Hampson, and M. Hatzipantelis. 1998. Navigation in a "virtual" maze: Sex differences and correlation with psychometric measures of spatial ability in humans. Evol. Hum. Behav. 19: 73-87.

Molnár, Orsolya, K. Hajer, B. Mészáros, J. Török, and G. Herczeg. 2013. Negative correlation between nuptial throat colour and blood parasite load in male European green lizards supports the Hamilton-Zuk hypothesis. Naturwissenschaften 100: 551-558.

Moore, I.T. and T.S. Jessop. 2003. Stress, reproduction, and adrenocortical modulation in amphibians and reptiles. Horm. Behav. 43: 39-47. 
Moore, I.T., J.P. Lerner, D.T. Lerner, and R.T. Mason. 2000. Relationships between annual cycles of testosterone, corticosterone, and body condition in male redspotted garter snakes (Thamnophis sirtalis concinnus). Physiol. Biochem. Zool. 73(3): 307-312.

Moore, J.A., C.H. Daugherty, and N.J. Nelson. 2009. Large male advantage: phenotypic and genetic correlates of territoriality in Tuartara. J. Herp. 43(4): $570-578$.

Moore, M.C. 1986. Elevated testosterone levels during non-breeding season territoriality in a fall-breeding lizard, Scelporus jarrovi. Horm. Behav. 88:215-226.

Moore, M.C. 1988. Testosterone control of territorial behavior: Tonic-release implants fully restore seasonal and short-term aggressive responses in free-living castrated lizards. Gen. Comp. Endocrinol. 70(3): 450-459.

Moore, M.C. and C.A. Marler. 1987. Effects of testosterone manipulations on nonbreeding season territorial aggression in free-living male lizards, Sceloporus jarrovi. Gen. Comp. Endocrinol. 65(2): 225-232.

Morgan, R.P.C. 2001. A simple approach to soil loss prediction: a revised MorganMorgan-Finney model. CATENA 44(4): 305-322.

Narayan, E.J., J.F. Cockrem, and J.M. Hero. 2013. Repeatibility of baseline corticosterone and short-term corticosterone stress responses, and their correlation with testosterone and body condition in a terrestrial breeding anuran (Platymantis vitiana). Comp. Biochem. Phys. A. 165: 304-312.

Néstor, P., A.M. Sabat, and W. O. McMillan. 2010. Spatial ecology of the endangered Mona Island iguana Cyclura cornuta stejnegeri: Does territorial behavior regulate density? Herpetol. Monogr. 24: 86-110.

Newhouse, P., C. Newhouse, and R.S. Astur. 2007. Sex differences in visual-spatial learning using a virtual water maze in pre-pubertal children. Behav. Brain. Res. 183: 1-7.

Newman, A.E.M., S.A. MacDougall-Shackleton, Y. An, B. Kriengwantana, and K.K. Soma. 2010. Corticosterone and dehydroepiadrosterone have opposing effects on adult neuroplasticity in the avian song control system. J. Comp. Neurol. 518: 3662-3678.

Pérez-Cañellas, M.M., E. Font, and J. M. García-Verdugo. 1997. Postnatal neurogenesis in the telencephalon of turtles: evidence for nonradial migration of new neurons from distant proliferative ventricular zones to the olfactory bulbs. Dev. Brain. Res. 101: 125-137. 
Pimentel, D. and N. Kounang. 1998. Ecology of oil erosion in ecosystems. Ecosystems 1(5): 416-426.

Pollock, N.B., L.K. Vredevoe, and E.N. Taylor. 2012. The effect of exogenous testosterone on ectoparasite loads in free-ranging western fence lizards. $J$. Exp. Zool. 317A: 447-454.

Rasika, S. F. Nottebohm, and A. Alvarez-Buylla. 1994. Testosterone increases the recruitment and/or survival of new vocal high center neurons in adult female canaries. Proc. Natl. Acad. Sci.91: 7854-7858.

Reboreda, J.C., N.S. Clayton, and A. Kacelnik. 1996. Species and sex differences in hippocampus size in parasitic and non-parasitic cowbirds. NeuroReport 7: 505-508.

Relyea, R.A., R.K. Lawrence, and S. Demarais. 2000. Home range of desert mule deer: Testing the body-size and habitat-productivity hypotheses. J. Wildl. Manage. 64(1): 146-153.

Riberio, L.B., B.M. Sousa, and S.C. Gomides. 2009. Range structure, microhabitat use, and activity patterns of the saxicolous lizard Tropidurus torquatus (Tropiduridae) on a rock outcrop in Minas Gerais, Brazil. Rev. Chil. Hist. Nat. 88: 577-588.

Rodríguez-Robles, J.A. 2003. Home ranges of Gopher snakes (Pituophis catenifer, Colubridae) in central California. Copeia 2003(2): 391-396.

Roof, R.L. and M.D. Havens. 1992. Testosterone improves maze performance and induces development of a male hippocampus female. Brain Res. 575 (1): 310-313.

Roth, E.D., W.I. Lutterschmidt, and D.A. Wilson. 2006. Relative medial and dorsal cortex volume in relation to sex differences in spatial ecology of a snake population. Brain Behav. Evolut. 67(2): 103-110.

Salvador, A. and J.P. Veiga. 2000. Does testosterone or coloration affect growth rates of adult males of the lizard Psammodromus algirus? Can.J. Zool. 78(8): 14631467.

Salvador, A., J.P. Veiga, J. Martín, and P. López. 1997. Testosterone supplementation in subordinate, small male lizards: consequences for aggressiveness, color development, and parasite load. Behav. Ecol. 8: 135-139.

Salvador, A., J.P. Veiga, J. Martin, P. Lopez, M. Abelenda, and M. Puerta. 1996. The cost of producing a sexual signal: testosterone increases the susceptibility of male lizards to ectoparasitic infestation. Behav. Ecol. 7: 145-150. 
Saucier, D.M., S.R. Shultz, A.J. Keller, C.M. Cook, and G. Binsted. 2008. Sex differences in object location memory and spatial navigation in Long...Evans rats. Anim. Cogn. 11: 129-137.

Schuett, G.W. and M.S. Grober. 2000. Post-fight levels of plasma lactate and corticosterone in male copperheads, Agkistrodon contortrix (Serpentes, Viperidae): differences between winners and losers. Physio, Behav. 71: 335341.

Schuett, G.W., H.J. Harlow, J.D. Rose, E.A. Van Kirk, W.J. Murdoch. 1996. Levels of plasma corticosterone and testosterone in male copperheads (Agkistrodon contortrix) following staged fights. Horm. Behav. 30(1): 60-68.

Scoular, K.M., W.C. Caffry, J.L. Tillman, E.S. Finan, S.K. Schwartz, B. Sinervo, and P.A. Zani. 2011. Multiyear home-range ecology of common side-blotched lizards in eastern Oregon with additional analysis of geographic variation in home-range size. Herpetol. Monogr. 25: 52-75.

Seredynski, A.L., G.F. Ball, J. Balthazart, T.D. Charlier. 2011. Specific activation of estrogen receptor alpha and beta enhances male sexual behavior and neuroplasticity in male Japanese quail. PLOS One 6(4): e18627. doi:10.1371/journal.pone. 0018627

Sheldahl, L.A. and E.P. Martins. 2000. The territorial behavior of western fence lizard, Sceloporus occidentalis. Herpetologica 56: 469-479.

Shettleworth, S.J. 1990. Spatial memory in food--storing birds. Phil. Trans. R. Soc. B 329: $143-151$.

Simão da Silva, E., T. Viçoso dos Santos, A.A. Hoeller, T. Souza dos Santos, G.V . Pereira, C. Meneghelli, A.I. Pezlin, M. Marcos dos Santos, M.S. Faria, M.A. Paschoalini, et al., 2008. Behavioral and metabolic effects of central injections of orexins/hypocretins in pigeons (Columba livia). Regul. Peptides 147(1-3): 9-18.

Sinervo, B., D.B Miles, W.A. Frankino, M. Klulowski, and D.F. DeNardo. 2000. Testosterone, endurance and Darwinian fitness: natural and sexual selection on the physiological bases of alternative male behaviors in side- - blotched lizards. Horm. Behav. 38(4): 222-223.

Sinsch, U. 2014. Movement ecology of amphibians: from individual migratory behavior to spatially structured populations in heterogeneous landscapes. Can.J. Zool. 92: 491-502.

Slotte, A. 1999. Effects of fish length and condition on spawning migration in Norwegian spring spawning herring (Clupea harengus L.). Sarsia 84: 111-127. 
Smith, G.R. 1995. Home range size, overlap, and individual growth in the lizard, Sceloporus virgatus. Acta Oecol. 16(4): 413-421.

Smith, G.T. E.A. Brenowitz, and J.C. Wingfield. 1997. Roles of photoperiod and testosterone in seasonal plasticity of the avian song control system. J. Neurobiol. 32(4): 426-442.

Spencer, K.A., K.L. Buchanan, S. Leitner, A.R. Goldsmith, and C.K. Catchpole. 2005. Parasites affect song complexity and neural development in a songbird. Proc. $R$. Soc. B 272: 2037-2043.

Spritzer, M.D., E. Ibler, W. Inglis, and M.G. Curtis. 2011. Testosterone and social isolation influence adult neurogenesis in the dentate gyrus of male rats. Neuroscience 195: 180-190.

Steffen, J.E. and C.C. Guyer. 2014. Display behaviour and dewlap colour as predictors of contest success in brown anoles. Biol. J. Linn. Soc. 111: 646-655.

Strand, C.R., M.S. Ross, S.L. Weiss, and P. Deviche. 2008. Testosterone and social context affect singing behavior but not song control region volumes in adult male songbirds in the fall. Behav. Process. 78: 29-37.

Stone, P.A. and T.A. Baird. 2002. Estimating lizard home range: The Rose model revisited. J. Herp. 36(3): 427-436.

Suri, D. and V.A. Vaidya. 2013. Glucocorticoid regulation of brain-derived neurotrophic factor: relevance to hippocampal structural and functional plasticity. Neuroscience 239: 196-213.

Swierk, L., M. Ridgway, and T. Langkilde. 2012. Female lizards discriminate between potential reproductive partners using multiple male traits when territory cues are absent. Behav. Ecol. Sociobiol. 66: 1033-1043.

Thompson, C.K., G.E. Bentley, and E.A. Brenowitz. 2007. Rapid seasonal-like regression of the adult avian song control system. PNAS 104(39): 15520-15525.

Thompson, C.W. and M.C. Moore. 1991. Throat color reliably signals status n male tree lizards, Urosaurus ornatus. Anim. Behav. 42: 745-753.

Tinkle, D.W. 1967. Home range density, dynamics, and structure of a Texas population of the lizard Uta stansburiana. Lizard Ecology: A Symposium. W.W. Milstead (Ed.), University of Missouri Press, Columbia, Missouri, USA. 
Tokarz, R.R. S. McMann, L. Seitz, and H. John-Alder. 1997. Plasma corticosterone and testosterone levels during the annual reproductive cycle of male brown anoles (Anolis sagrei). Physiol.Zool. 71(2): 139-146.

Tokarz, R.R. 1995. Importance of androgens in male territorial acquisition in the lizard Anolis sagrei: an experimental test. Anim. Behav. 49(3): 661-669.

Traish, A.M. 2014. Testosterone and weight loss: the evidence. Curr. Opin. Endocrinol.Diabetes Obes. 21(5): 312-322.

Trewhella, W.J., S. Harris, and F.E. McAllister. 1988. Dispersal distance, home-range size and population density in the red fox (Vulpes vulpes): A quantitative analysis. J.Appl.Ecol. 25: 423-434.

Trigo, S., and P.G. Mota. 2014. What is the value of a yellow patch? Assessing the signaling role of yellow colouration in the European serin. Behav. Ecol. Sociobiol. 69: 481-490.

Tsujino, N. and T. Sakurai. 2013. Role of orexin in modulating arousal, feeding, and motivation. Front. Behav. Neurosci. 7: 28-42.

Urbán, N. and F. Guillemot. 2014. Neurogenesis in the embryonic and adult brain: same regulators, different roles. Front. Cell. Neurosci. 8: 396.

Vangestel, C., B.P. Braeckman, H. Mathevem and L. Lens. 2008. Constraints on home range behavior affect nutritional condition in urban house sparrows (Passer domesticus). Biol.J.Linn. Soc. 101: 41-50.

Václav, R., P. Prokop, and V. Fekiač. 2007. Expression of breeding coloration in European green lizards (Lacerta viridis): variation with morphology and tick infestation. Can.J.Zool. 85: 1199-1206.

Wack, C.L., S.F. Fox, E.C. Hellgren, and M.B. Lovern. 2007. Effects of sex, age, and season of plasma steroids in free-ranging Texas horned lizards (Phrynosoma cornutum). Gen. Comp. Endocrinol. 155(3): 589-596.

Wainwright, S.R., S.E. Lieblich, L.A.M. Galea. 2011. Hypogonadism predisposes males to the development of behavioural and neuroplasticity depressive phenotypes. Psychoneuroendocrino. 36: 1327-1341.

Weiss, S.L. and M.C. Moore. 2004. Activation of aggressive behavior by progesterone and testosterone in male tree lizards, Urosaurus ornatus. Gen. Comp. Endocrinol. 136(2): 282-288. 
Wingfield, J.C. and K.K. Soma. 2002. Spring and autumn territoriality in song sparrows: sane behavior, different mechanisms? Integr. Comp. Biol. 42: 1120.

Wone, B. and B. Beauchamp. 2003. Movement, home range and activity patterns of the horned lizard, Phynosoma mcallii. J. Herp. 37: 679-686.

Woolley, D.G., B. Vermaercke, H.O. de Beeck, J. Wagemans, I. Gantois, R. D'Hooge, S.P. Swinnen, and N. Wenderoth. 2010. Sex differences in human virtual water maze performance: Novel measures reveal the relative contribution of directional responding and spatial knowledge. Behav. Brain Res. 208: 408-414.

Xiao, L. and C.L. Jordan. 2002. Sex differences, laterality, and hormonal regulation of androgen receptor immunoreactivity in the rat hippocampus. Horm. Behav. 42: 327336. 


\section{APPENDICES}

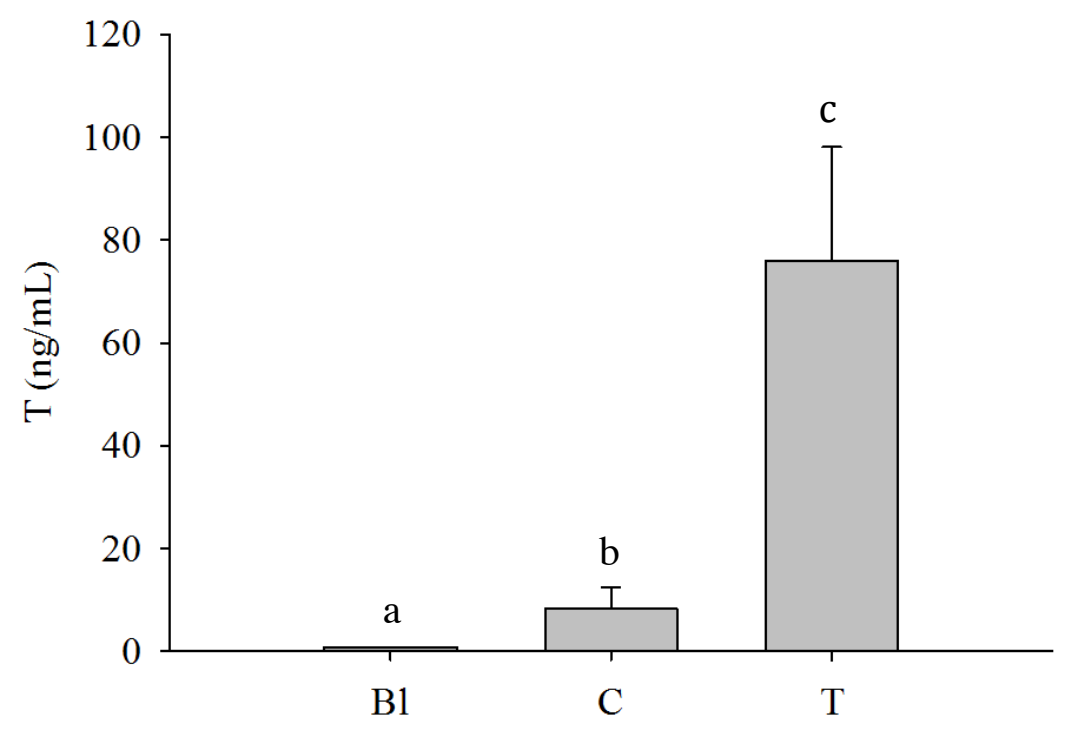

Figure 1.1. Testosterone $(T)$ levels $(\mathrm{ng} / \mathrm{mL})$ plotted as mean \pm SEM values of adult male Sceloporus occidentalis. $\mathrm{Bl}=$ blank implanted individuals, $\mathrm{C}=$ unmanipulated controls, and $\mathrm{T}=\mathrm{T}$ implanted individuals. $\mathrm{n}=4$ per group. Different lettering indicates significant differences $(\mathrm{p}<0.05)$. 


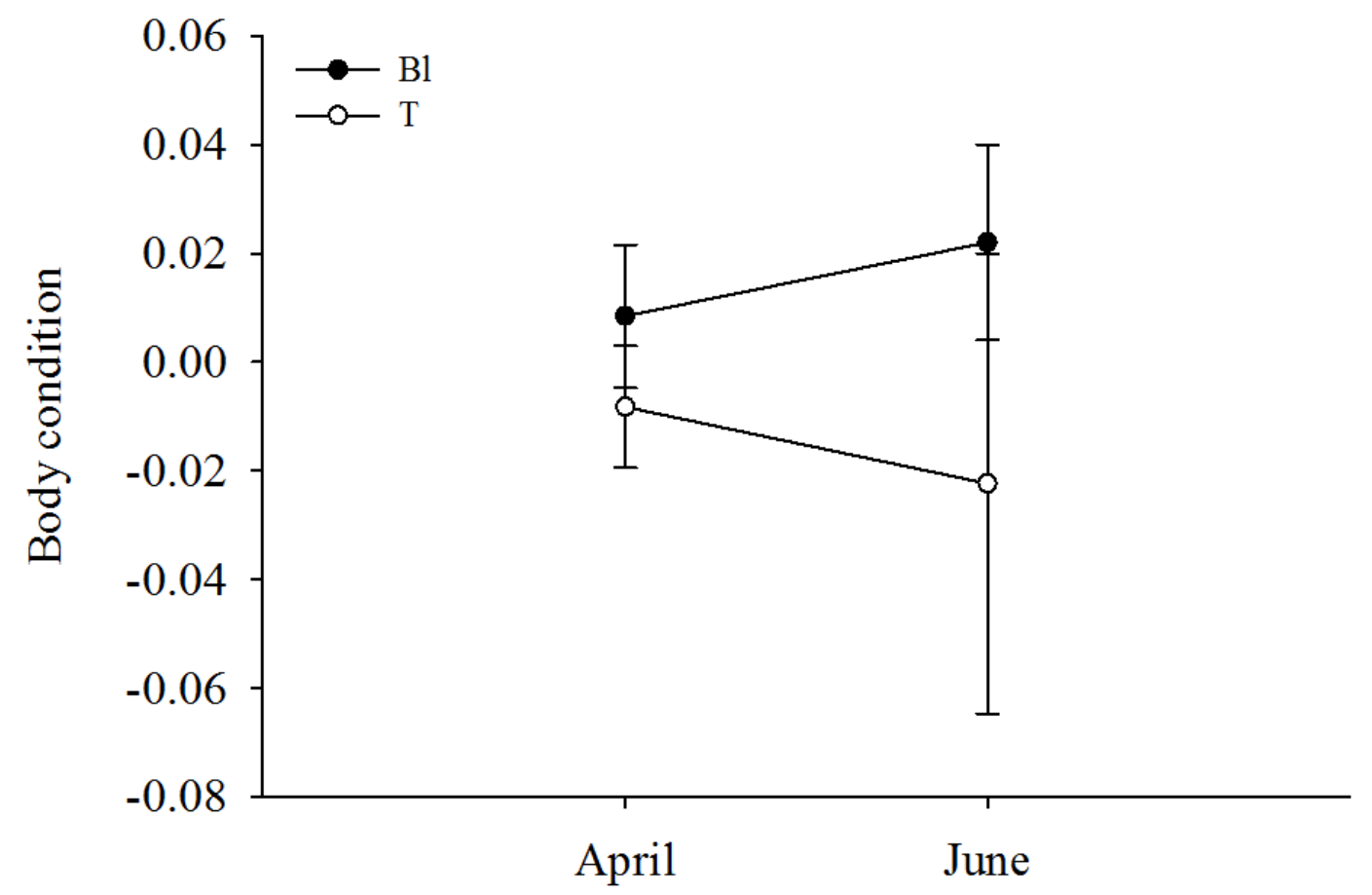

Figure 1.2. Body condition (mean \pm SEM) of testosterone $(T)$ and blank implanted (BI) individuals of adult male Sceloporus occidentalis. Body condition was determined by calculating the residual after regressing log transformed snout-vent length and log transformed body mass. There were no significant differences between groups, time periods, or the interaction between group and time period $n=4$ per group. 


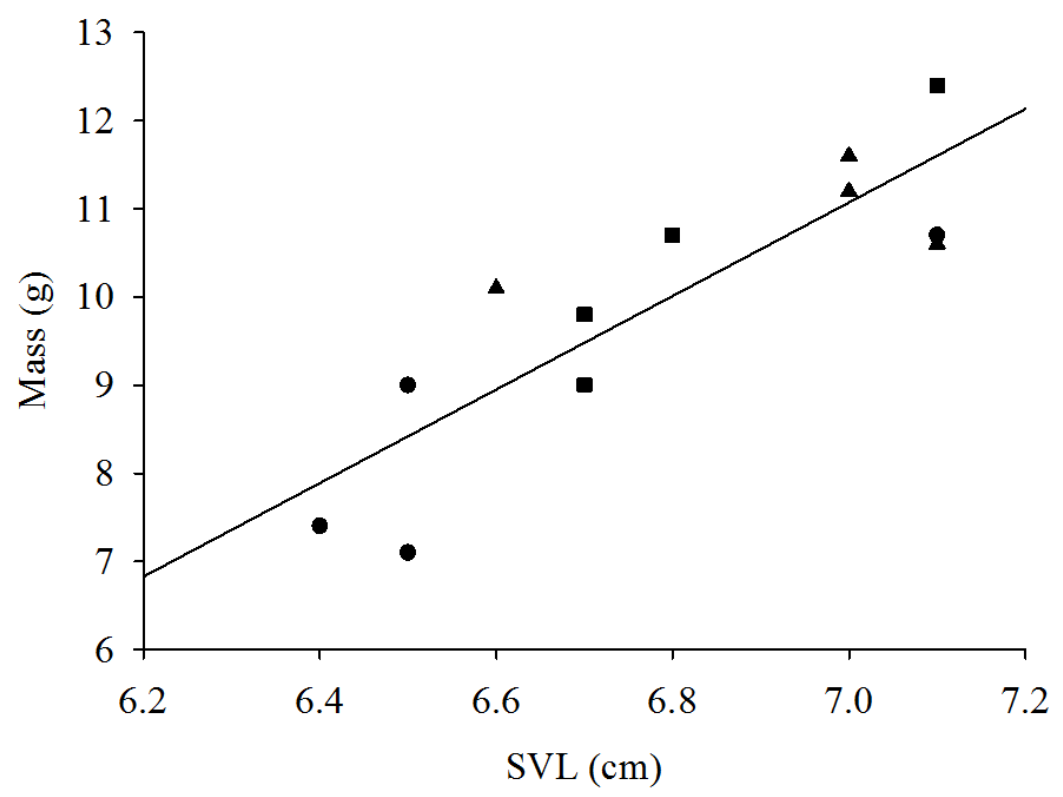

Figure 1.3. Relationship between snout-vent length (SVL) and body mass of recaptured individuals of adult male Sceloporus occidentalis. Triangles represent blank implanted individuals, squares represent unmanipulated controls, and circles represent testosterone-implanted subjects. SVL significantly correlated with body mass $(\mathrm{p}=0.002) . \mathrm{n}=4$ per group. 


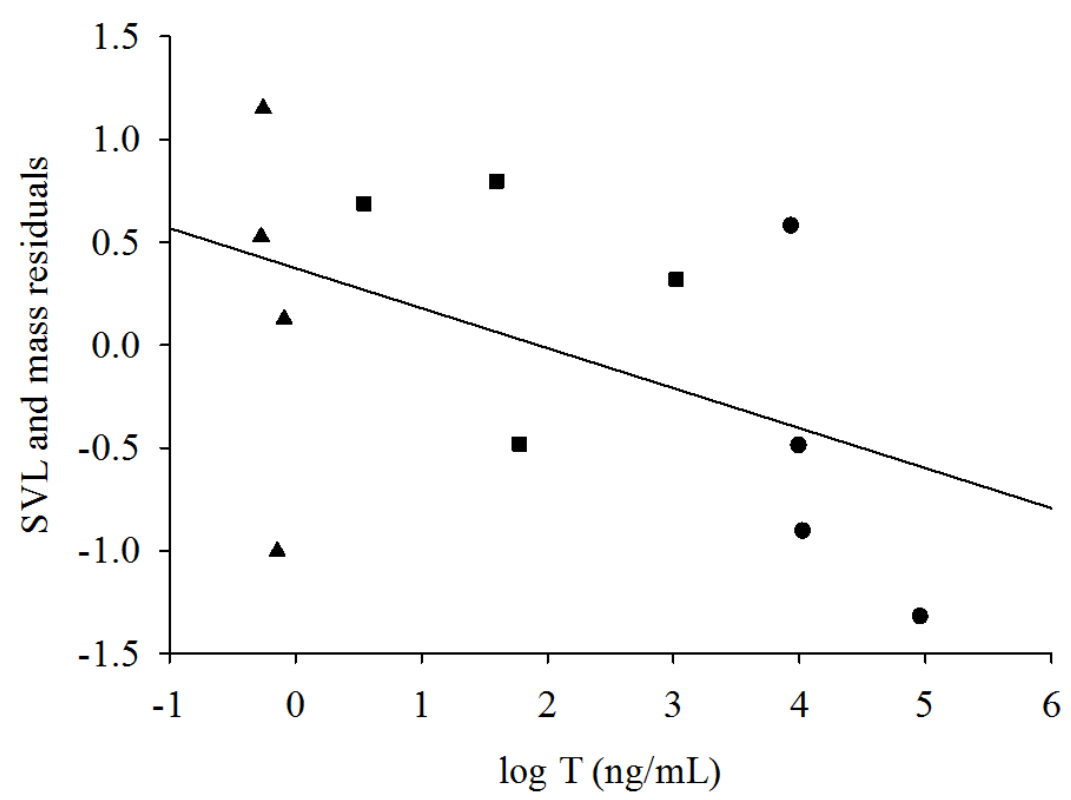

Figure 1.4. Relationship between testosterone $(T)$ and body mass controlling for snout-vent length (SVL) of adult male Sceloporus occidentalis. Triangles represent blank implanted individuals, squares represent unmanipulated controls, and circles represent testosterone-implanted subjects. Controlling for body mass, $\mathrm{T}$ trended to cause a non-significant decrease in $\mathrm{SVL}(\mathrm{P}=0.076)$. $\mathrm{n}=4$ per group. 


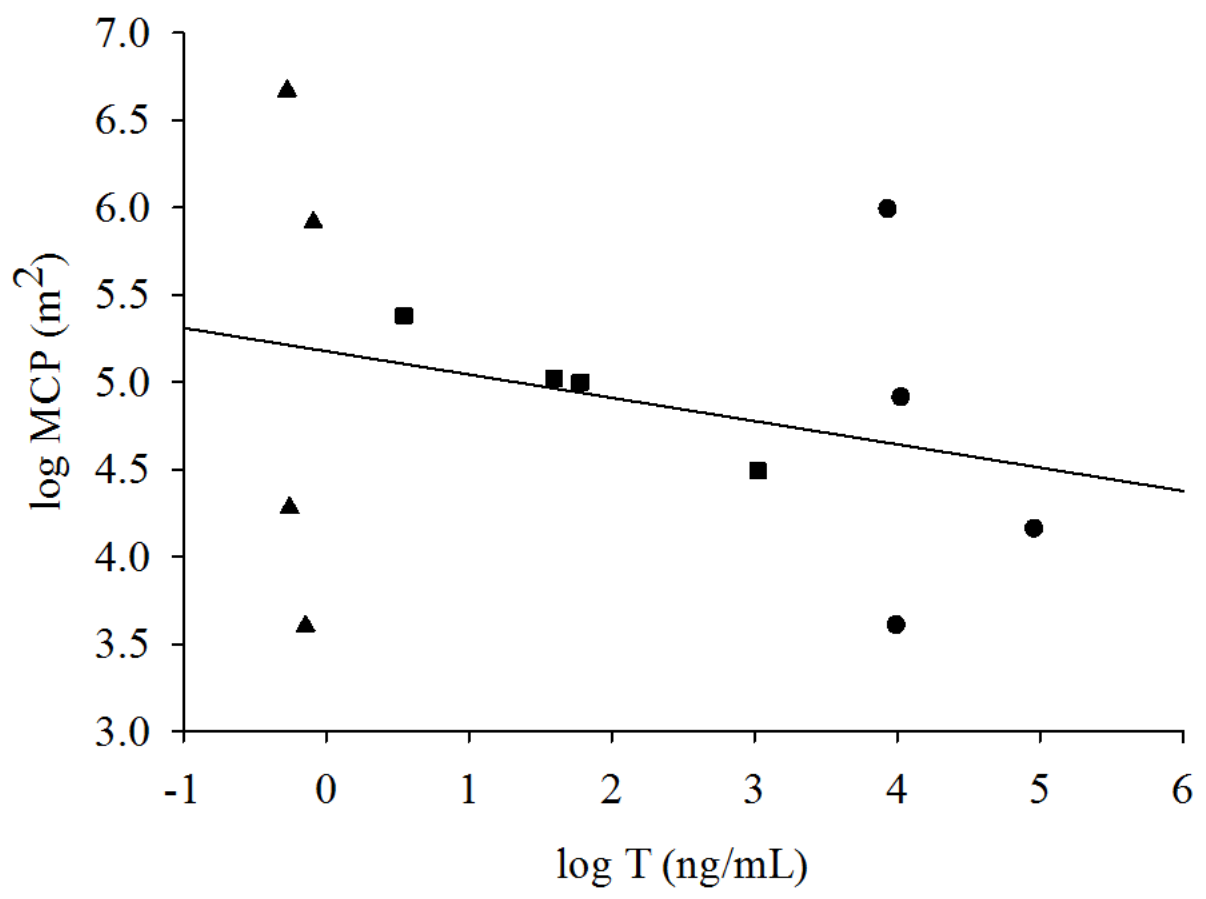

Figure 1.5. Mean minimum convex polygons (MCP; $\mathrm{m}^{2} \pm 1$ SEM) of adult male Sceloporus occidentalis. Triangles represent blank implanted individuals, squares represent unmanipulated controls, and circles represent testosterone-implanted subjects. $T$ did not affect $\log$ MCP $(\mathrm{p}=0.96)$. $\mathrm{n}=4$ per group. 


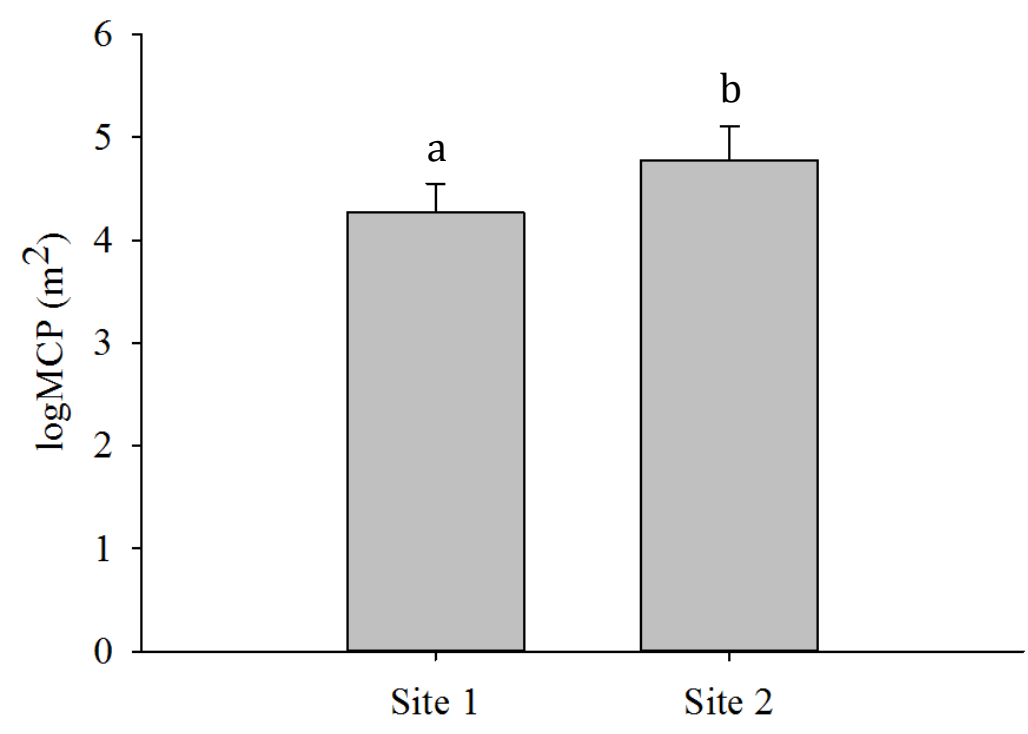

Figure 1.6. Mean log transformed minimum convex polygons $\left(\mathrm{MCP} ; \mathrm{m}^{2} \pm \mathrm{SEM}\right)$ of adult male Sceloporus occidentalis. Different lettering indicates significance $(\mathrm{p}=0.032)$. $\mathrm{n}=6$ per site. 


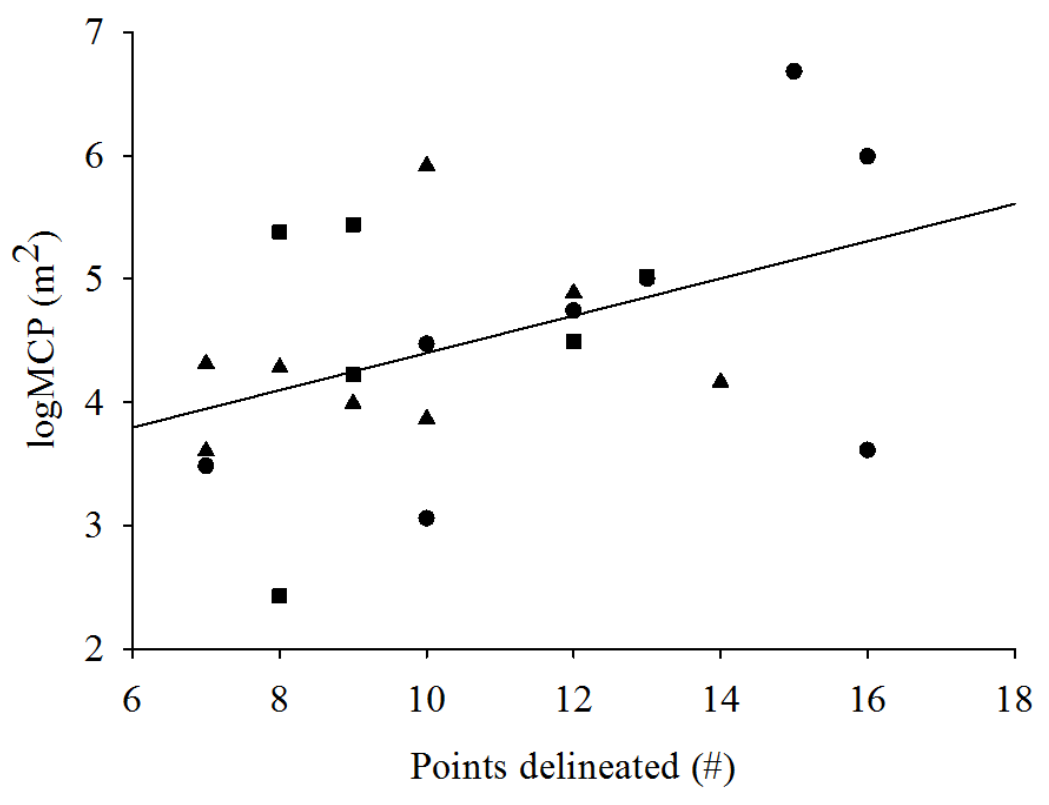

Figure 1.7. Relationship between the number of points used to delineate minimum convex polygon (MCP) and $\log \mathrm{MCP}\left(\mathrm{m}^{2}\right)$ of adult male Sceloporus occidentalis. Triangles represent blank implanted individuals $(n=8)$, squares represent unmanipulated controls $(n=7)$, and circles represent testosterone implanted subjects $(n=7)$. The number of points delineated significantly affected $\log \mathrm{MCP}(\mathrm{p}=0.04)$. 


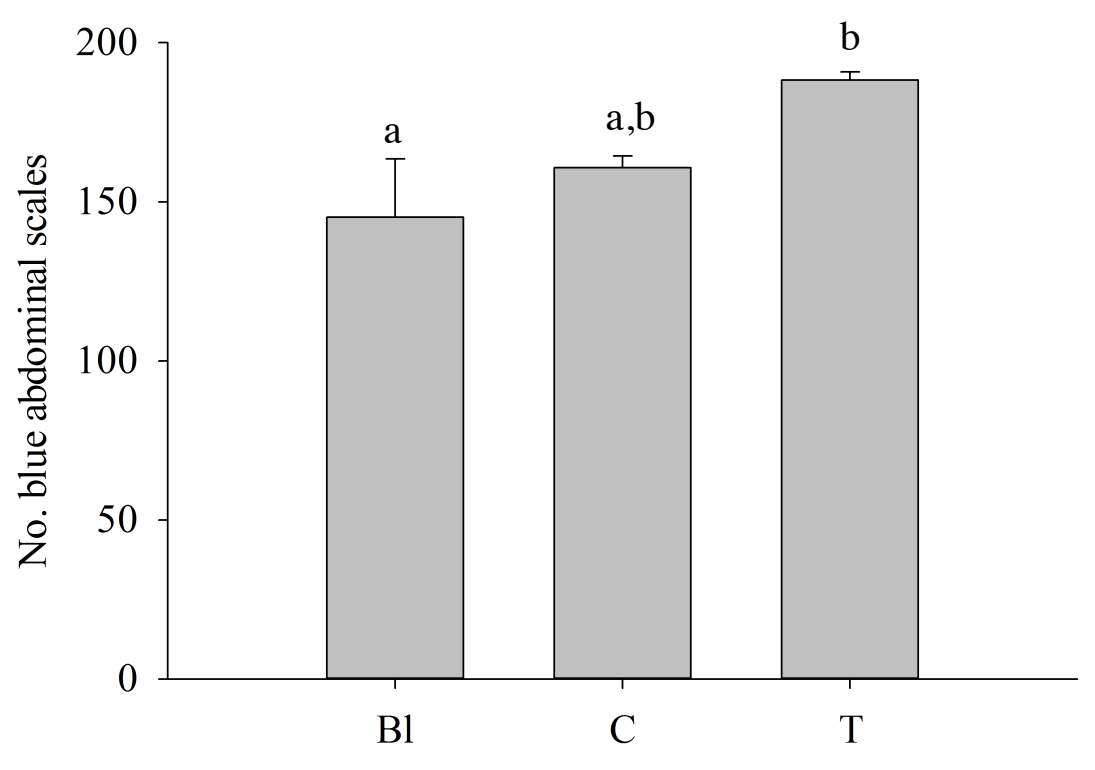

Figure 1.8. Mean number of blue abdominal scales (count+SEM) of adult male Sceloporus occidentalis. $\mathrm{B}=$ blank implanted individuals, $\mathrm{C}=$ unmanipulated controls, and $\mathrm{T}=$ testosterone-implanted individuals. $\mathrm{n}=4$ per group. $\mathrm{T}$-implanted individuals had a higher number of blue abdominal badges $(\mathrm{p}<0.05)$. Different lettering indicates significance. 


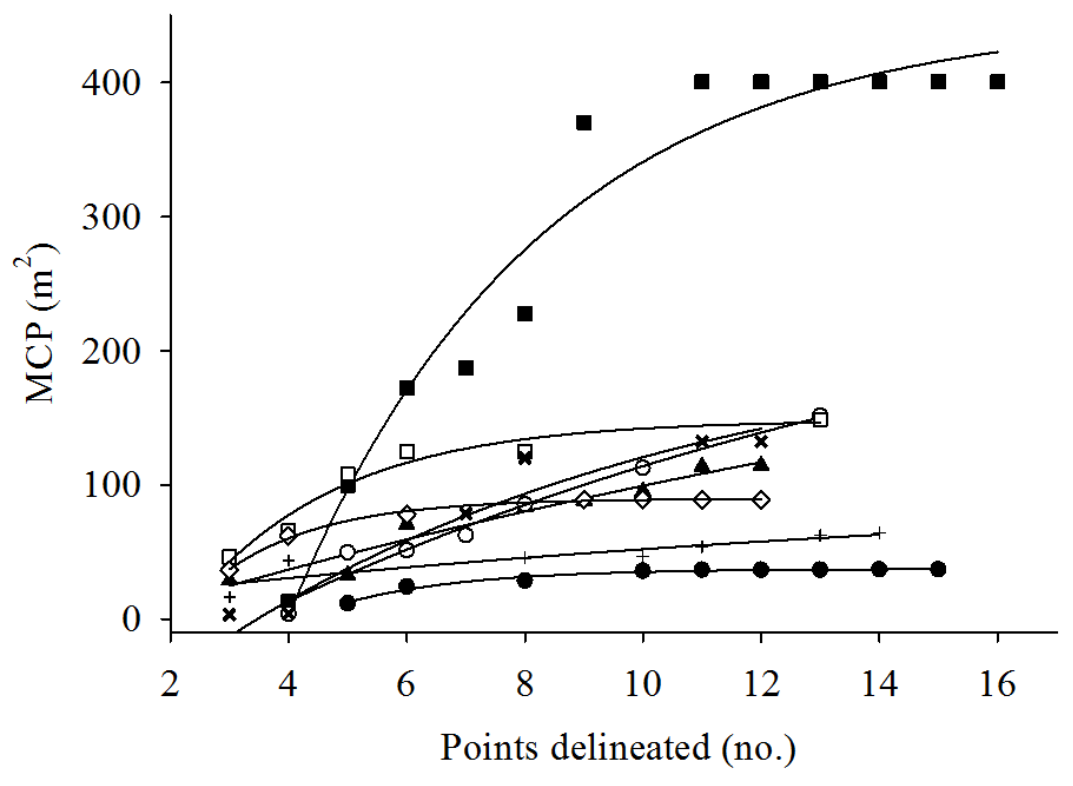

Figure 1.9. Change in minimum convex polygons (MCPs) relative to the number of spatial observation points used to delineate the MCP of adult male Sceloporus occidentalis. Each line represents a different individual $(\mathrm{n}=8)$ who's MCP was calculated by randomly removing one GPS point. Lines are plotted using an exponential rise to maximum function. The minimum number of sightings required to identify an accurate MCP estimate was determined by using a repeated measures ANOVA with points delineated as a categorical variable. Post-hoc tests revealed that five sightings was significantly different from other sightings $(\mathrm{p}<0.05)$. 


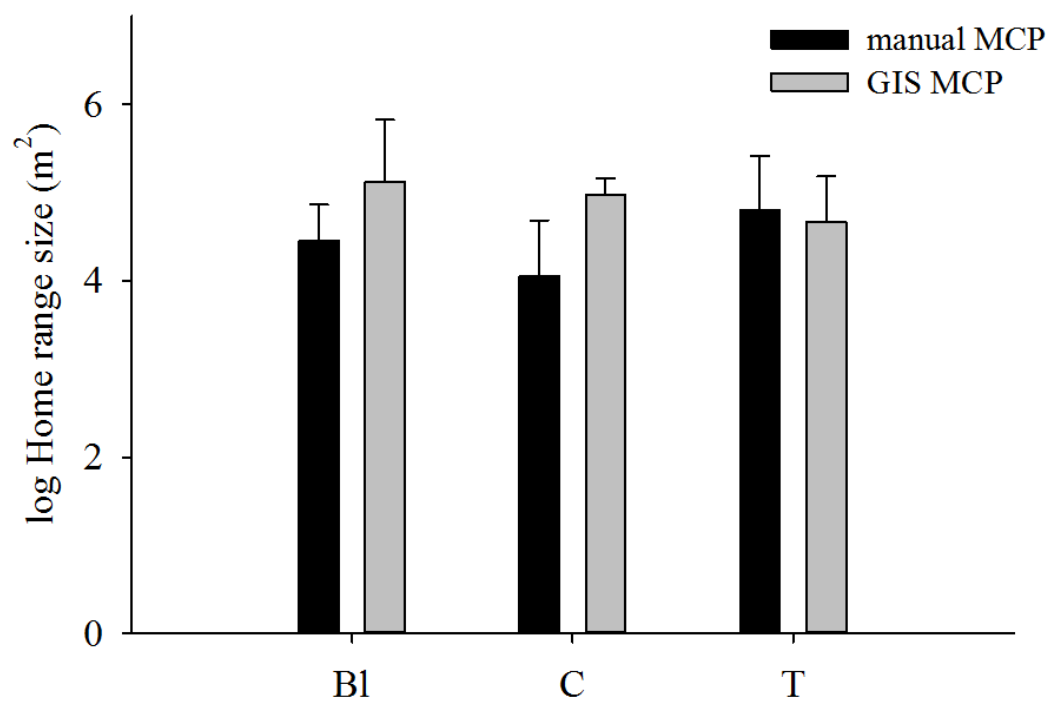

Figure 1.10. Comparison of home range size $\left(\mathrm{m}^{2} \pm \mathrm{SEM}\right)$ measurement techniques of adult male Sceloporus occidentalis. Manual minimum convex polygons (MCPs) measurements included marking locations with flags via photography and measuring distances between flags with a tape measure and compass. Geographic information system (GIS) MCPs were measured by delineating polygons in ArcGIS 9.2. There were no differences in group home range sizes. However, manual MCPs significantly differed from GIS MCPs ( $\mathrm{p}=0.049)$. Bl=blank implanted individuals, $\mathrm{C}=$ unmanipulated controls, and $\mathrm{T}=$ testosterone-implanted individuals. $\mathrm{n}=4$ per group. 


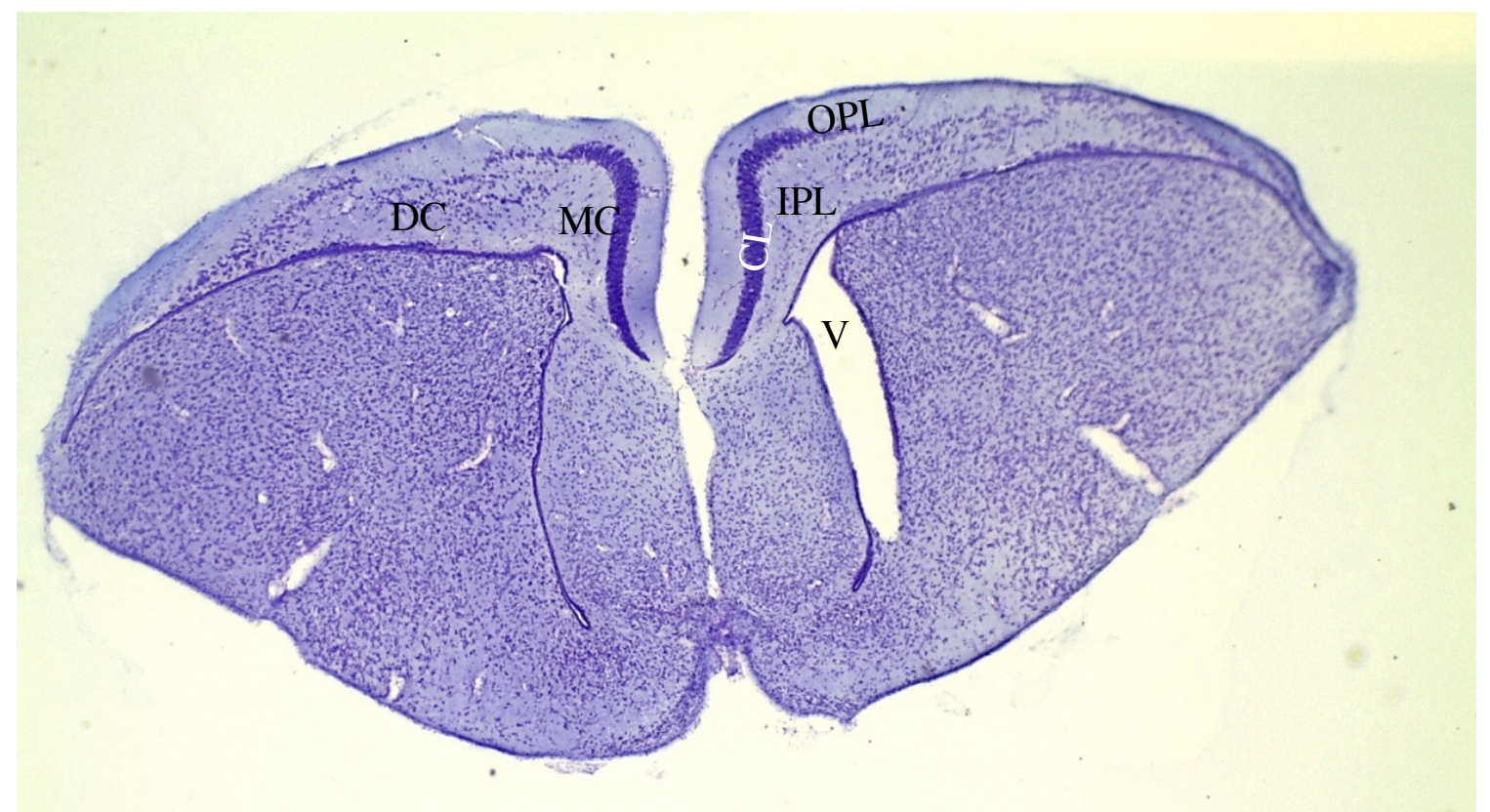

Figure 2.1. Cresyl violet stained section through the telencephalon of an adult male Sceloporus occidentalis (20x). Medial cortex (MC), dorsal cortex (DC), ventricle (V), inner plexiform layer (IPL), cell layer (CL), and outer plexiform layer (OPL). 


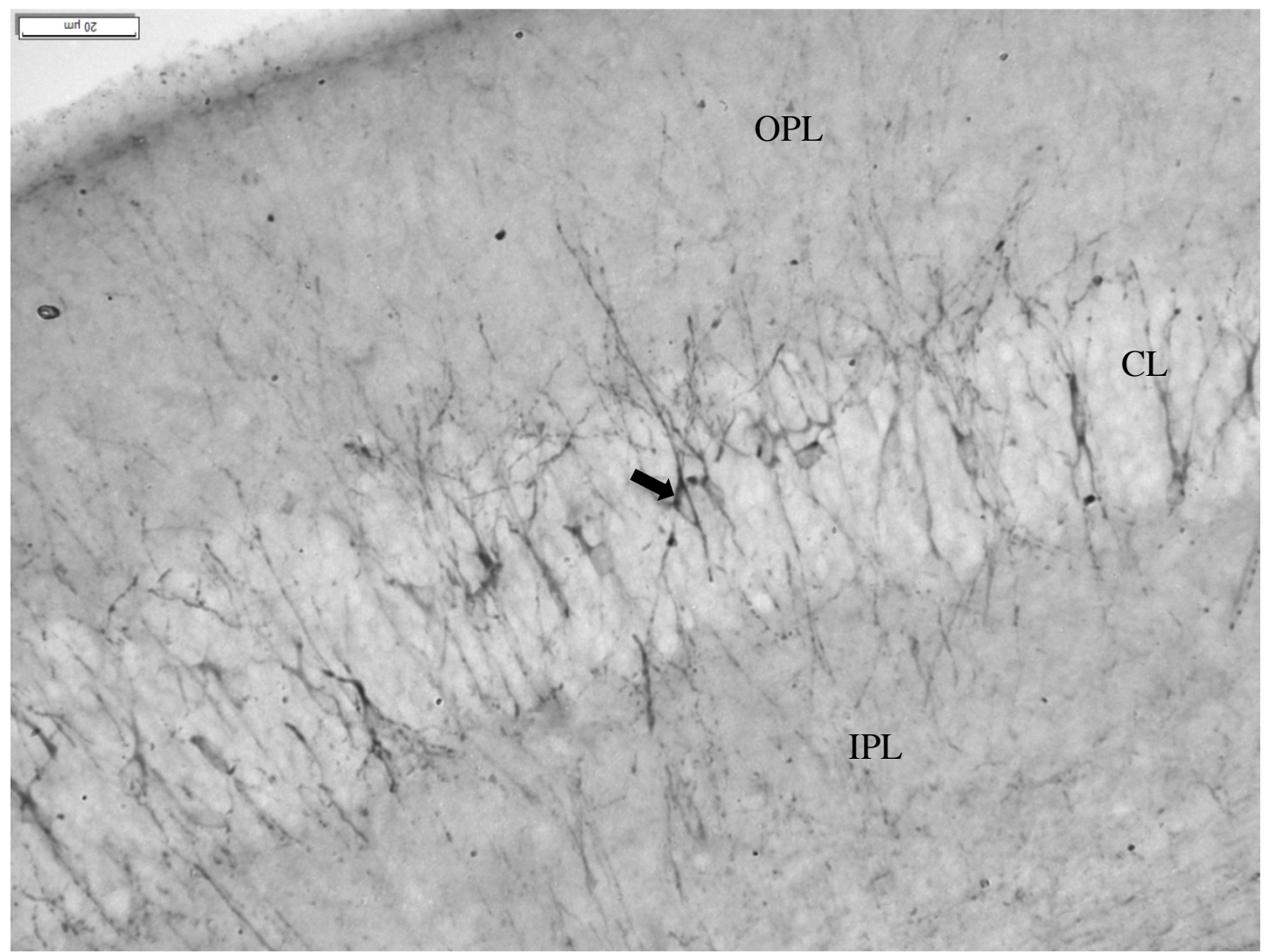

Figure 2.2. Doublecortin-immunoreactive (DCX-ir) cells in the medial cortex (MC; 200x) of adult male Sceloporus occidentalis. Arrow indicates a cell expressing DCX. Inner plexiform layer (IPL), cell layer (CL), and outer plexiform layer (OPL). 


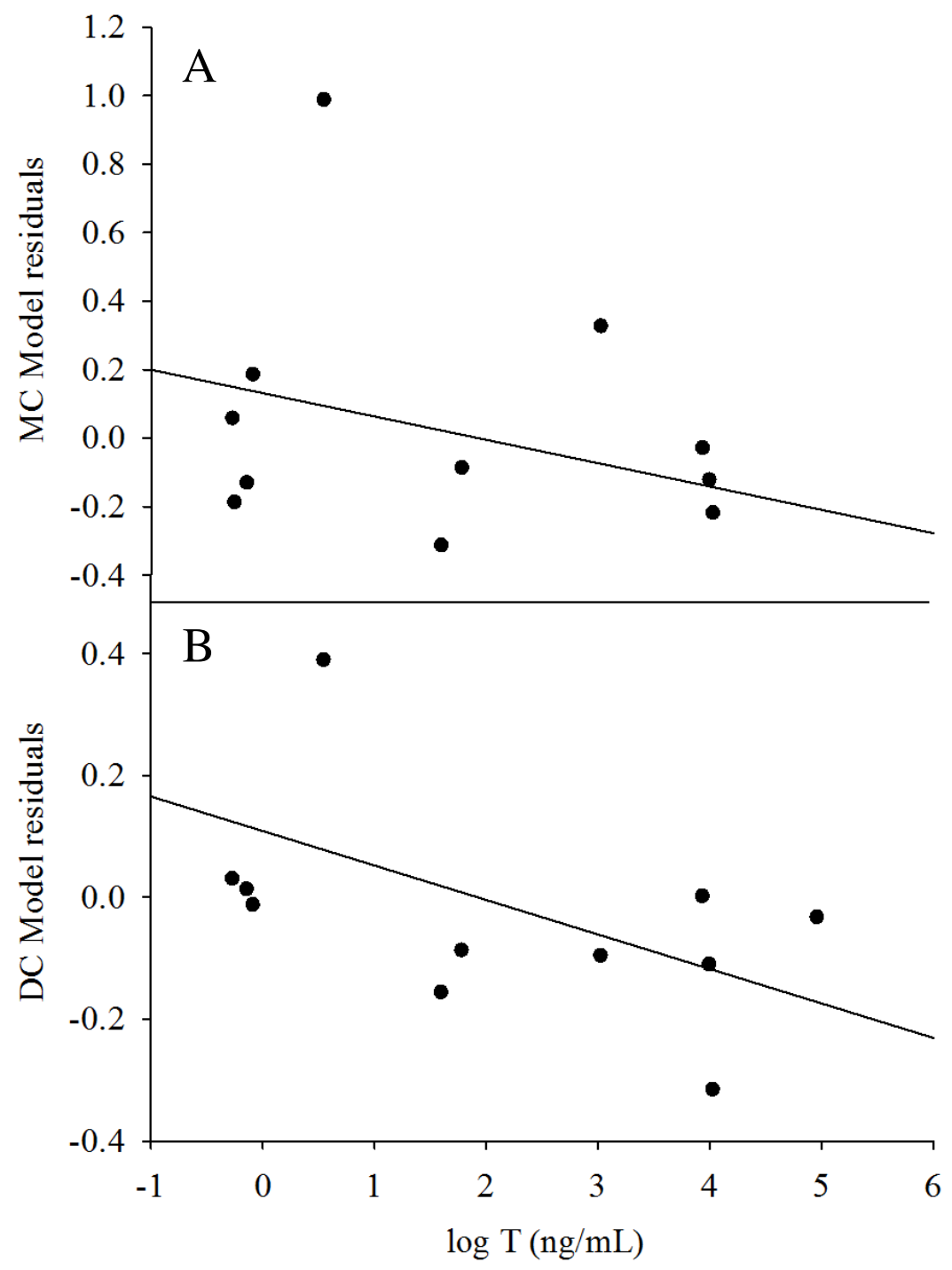

Figure 2.3. Model residuals of all variables in the model excluding plasma testosterone (T) concentration $(\mathrm{ng} / \mathrm{mL})$ for the medial cortex $(\mathrm{A})$ and dorsal cortex (B) of adult male Sceloporus occidentalis. Variables included total telencephalon volume, home range. $n=12$. 

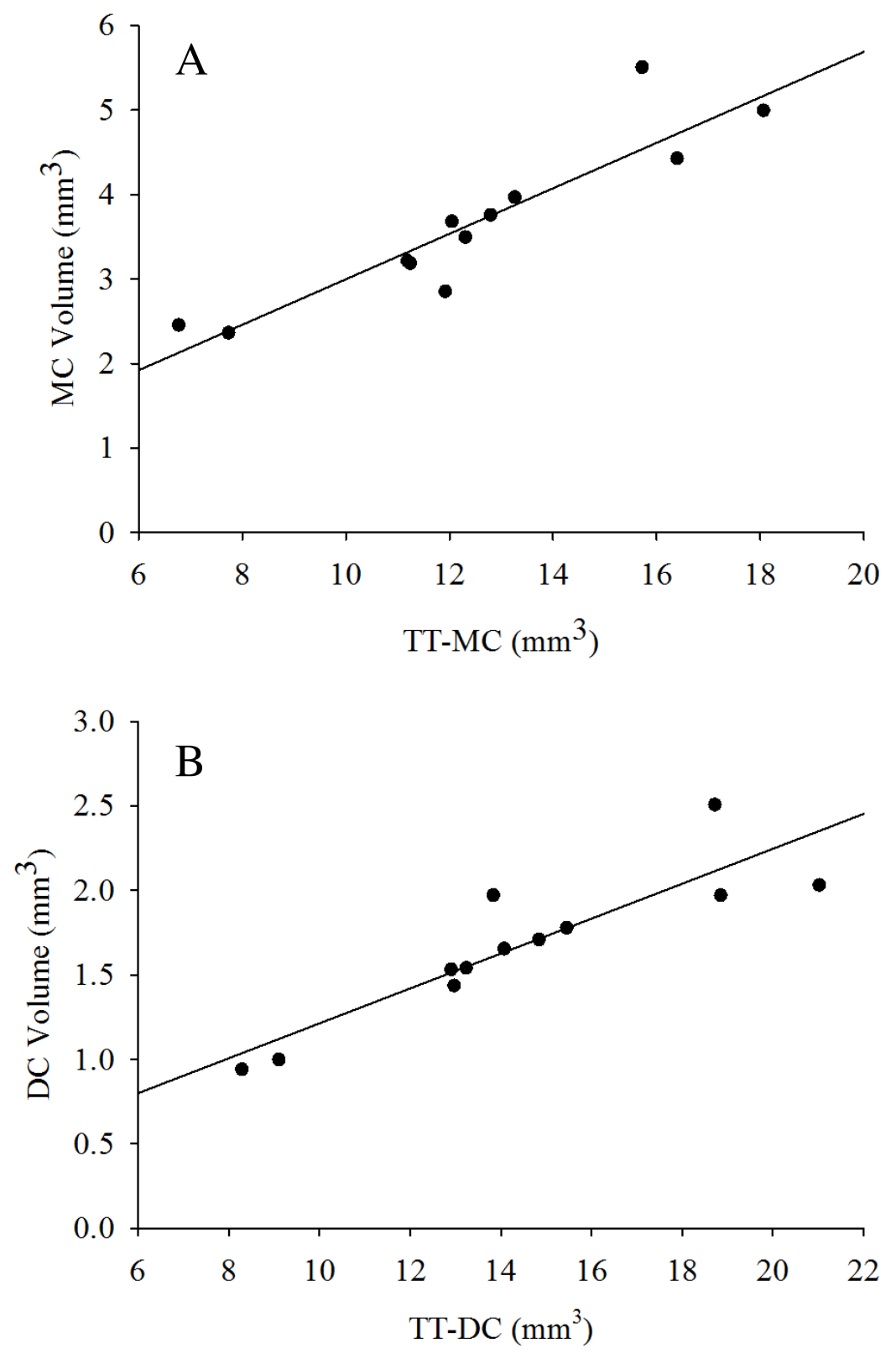

Figure 2.4. Relationship between total telencephalon volumes $\left(\mathrm{TT} ; \mathbf{~ m m}^{3}\right)$ excluding the region of interest and the medial cortex (MC; A) and dorsal cortex (DC; B) of adult male Sceloporus occidentalis. Both MC and DC increased with increasing TT $(\mathrm{p}<0.001$ and $\mathrm{p}<0.001$ respectively). $\mathrm{n}=12$. 

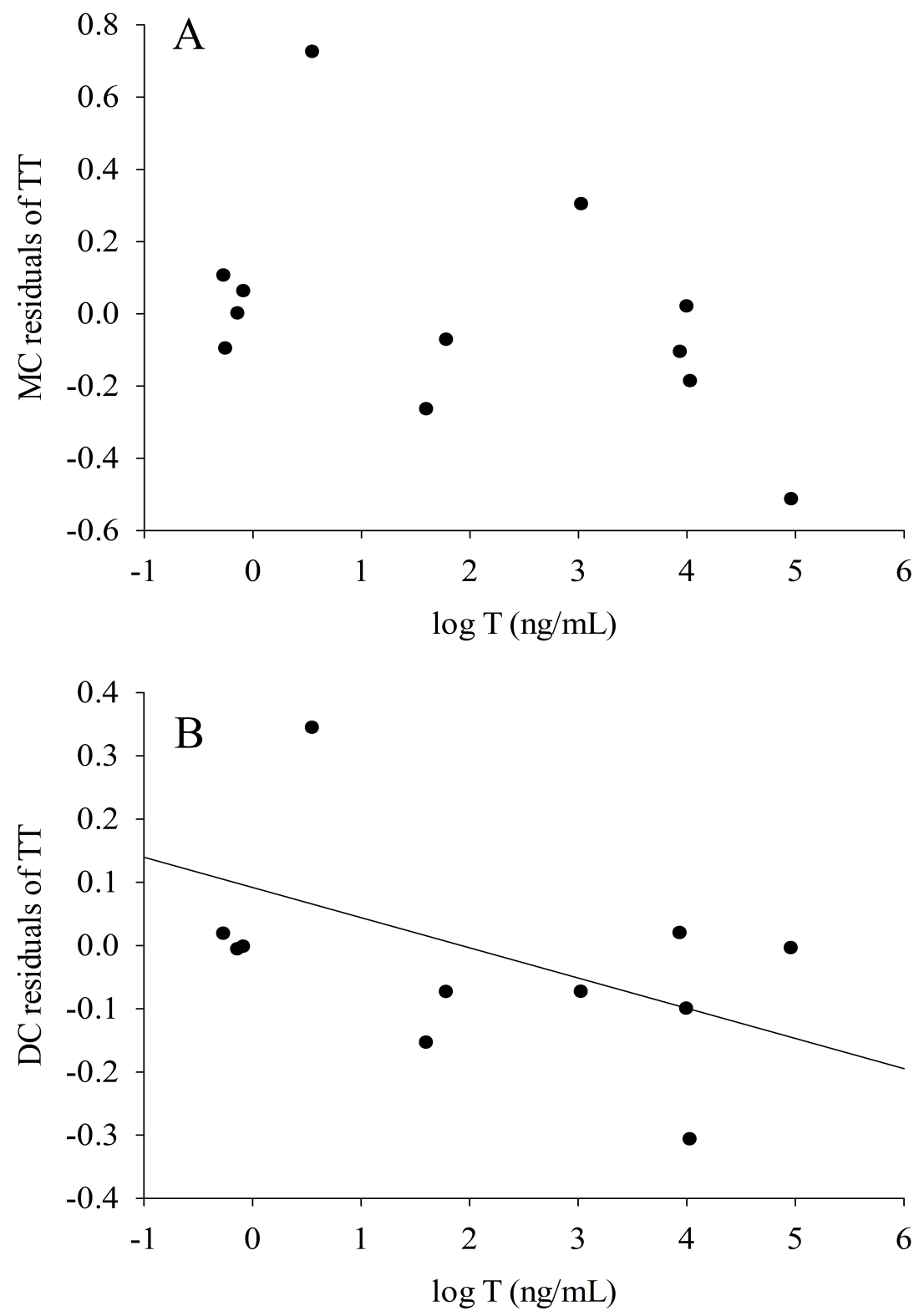

Figure 2.5. Relationship between plasma testosterone (T) concentration $(\mathrm{ng} / \mathrm{mL})$ and the medial cortex (MC; A) and dorsal cortex (DC; B) controlling for size of total telencephalon (TT) of adult male Sceloporus occidentalis. $n=12$. T affect DC, but not $\mathrm{MC}(\mathrm{p}=0.245$ and $\mathrm{p}=0.048$ respectively). 

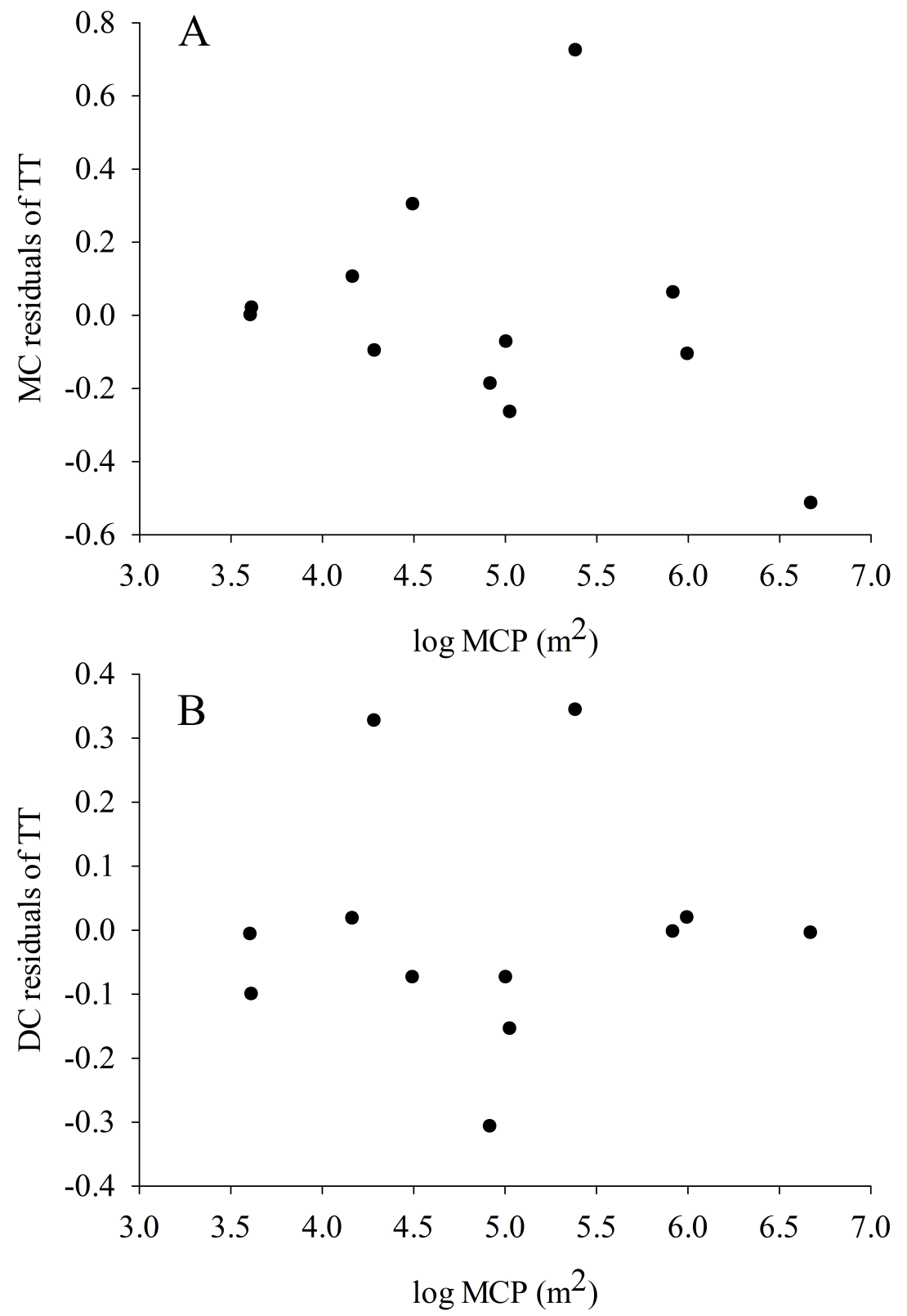

Figure 2.6. Relationship between home range size calculated as minimum convex polygon (MCP) and the medial cortex (MC; A) and dorsal cortex (DC; B), controlling for size of total telencephalon (TT) of adult male Sceloporus occidentalis. Residuals were calculated using the distance to the trendline in the above figure (2.9) $\mathrm{Bl}=$ blank implanted individuals, $\mathrm{C}=$ unmanipulated controls, and $\mathrm{T}=$ testosterone implanted individuals. $\mathrm{n}=12$. Log MCP did not correlate with either $\mathrm{MC}$ or $\mathrm{DC}(\mathrm{p}=0.885$ and $\mathrm{p}=0.259$ respectively). 

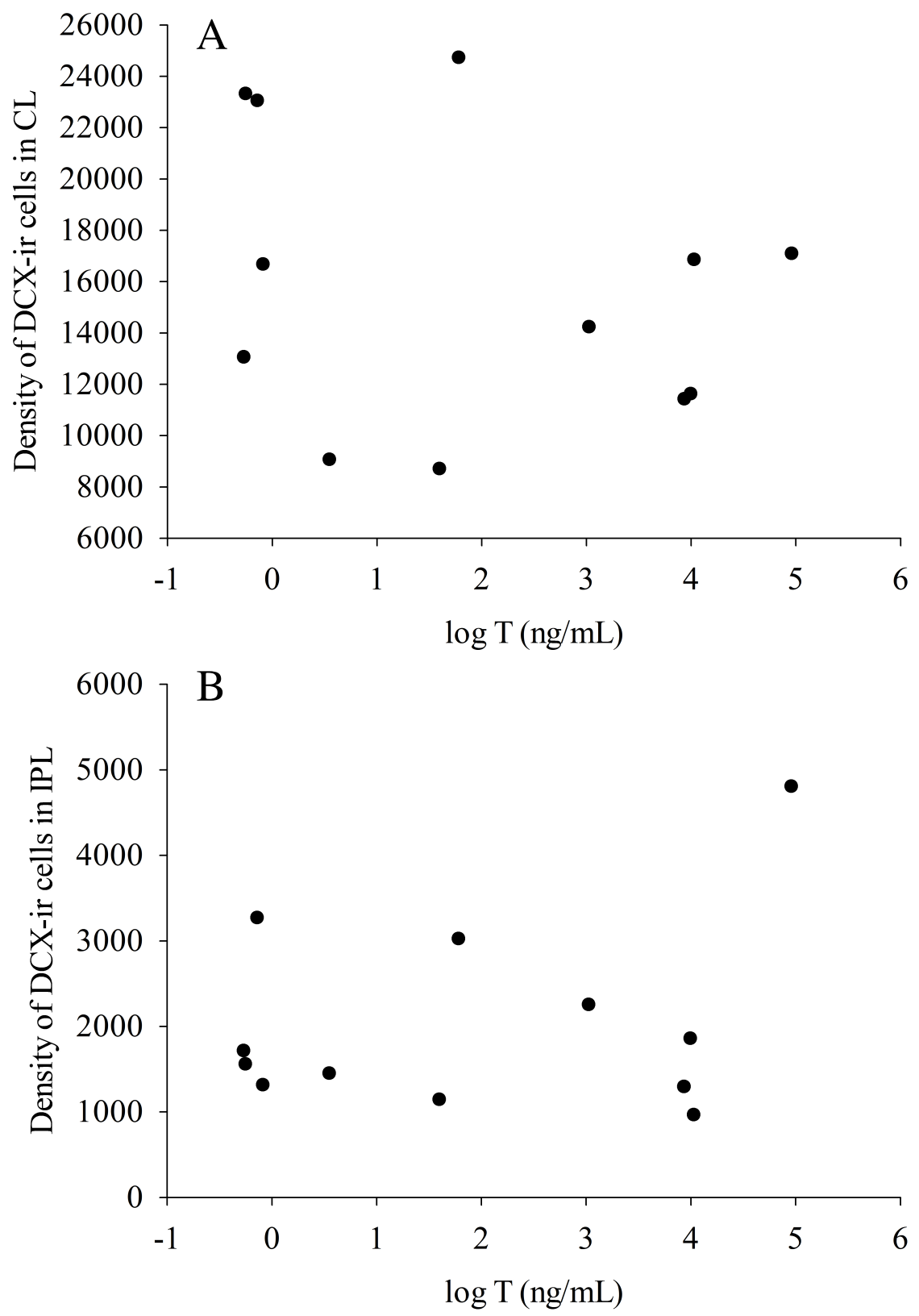

Figure 2.7. Relationship between plasma testosterone $(T)$ concentration $(\mathrm{ng} / \mathrm{mL})$ and model residuals of the density of doublecortin-immunoreactive (DCX-ir; count $\left./ \mathrm{mm}^{3}+\mathrm{SEM}\right)$ cells in the cell layer $(\mathrm{CL} ; \mathrm{A})$ and inner plexiform layer (IPL; B) of adult male Sceloporus occidentalis. Variables included minimum complex polygon and body condition. $\mathrm{n}=12$. $\mathrm{T}$ did not affect DCX-ir cells in either the CL or IPL ( $\mathrm{p}=0.712$ and $\mathrm{p}=0.907$ respectively). 

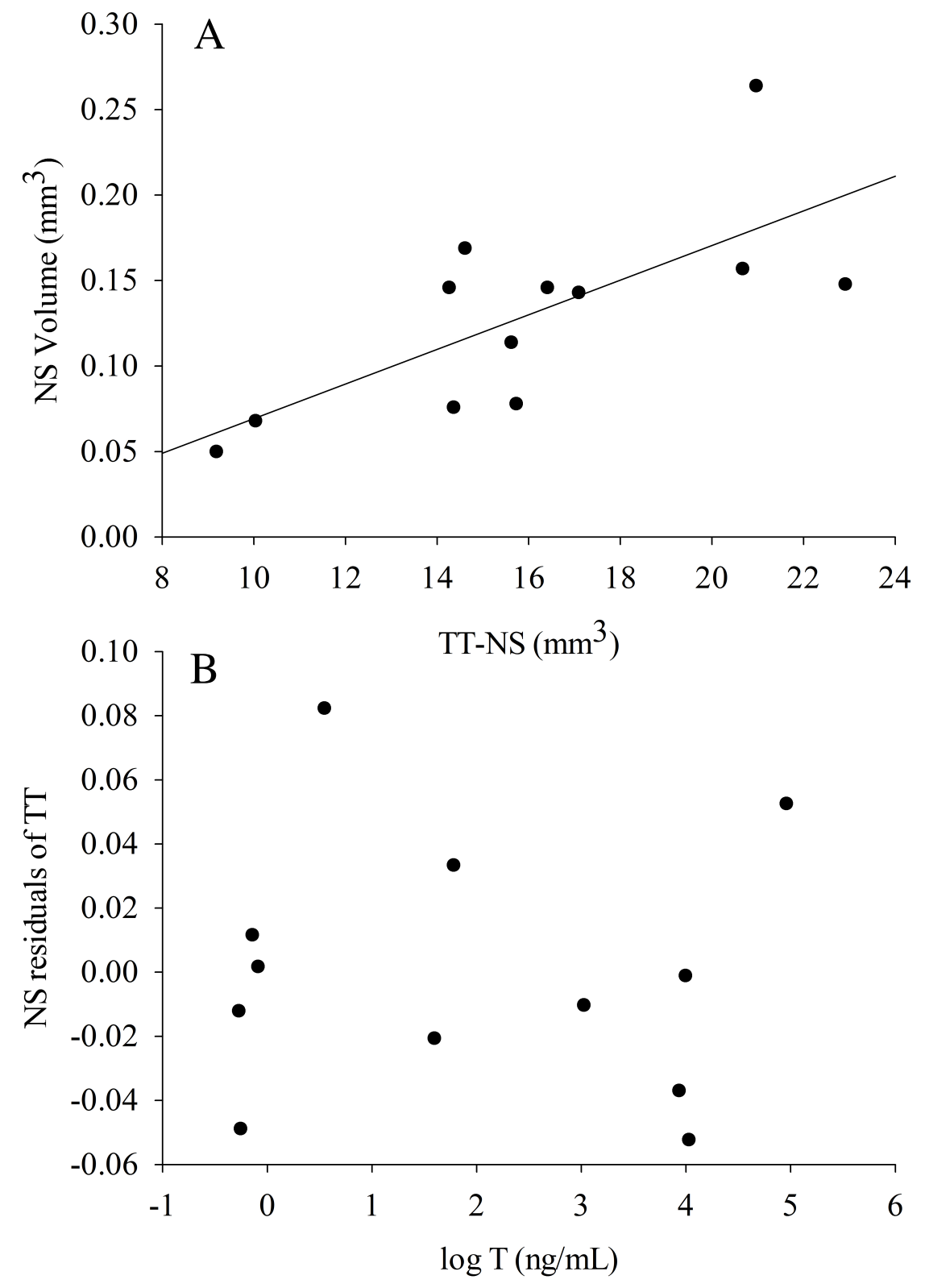

Figure 2.8. Relationship between total telencephalon volume (TT; $\mathbf{~ m m}^{3}$ ) excluding the nucleus sphericus (NS) and the NS (A) and the effect of plasma testosterone (T) concentration $(\mathrm{ng} / \mathrm{mL})$ on NS volume controlling for TT (B) of adult male Sceloporus occidentalis. $\mathrm{n}=12$. As TT increased, NS increased $(\mathrm{p}=0.017)$. $\mathrm{T}$ did not affect NS volume ( $\mathrm{p}=0.875)$. 